\title{
Damaging behavior of masonry arch bridges: analysis of 'Ponte delle Torri' in Spoleto, Italy
}

\author{
Daniela Addessi ${ }^{1}$, Domenico Liberatore and Mariacarla Nocera
}

${ }^{1}$ Corresponding author: Dr Daniela Addessi

Department of Structural and Geotechnical Engineering, Sapienza University of Rome, Via Eudossiana 18, 00184 Rome, Italy

tel: +390644585299

fax: +39064884852

e-mail: daniela.addessi@uniroma1.it 


\title{
Damaging behavior of masonry arch bridges: analysis of 'Ponte delle Torri' in Spoleto, Italy
}

\author{
Daniela Addessi, Domenico Liberatore and Mariacarla Nocera \\ Department of Structural and Geotechnical Engineering, Sapienza University of Rome \\ Via Eudossiana 18, 00184 Rome, Italy
}

\begin{abstract}
Damage effects on the dynamic response of the masonry bridge 'Ponte delle Torri' in Spoleto are investigated. To model ancient masonry material response, a scalar damage variable is introduced in the stress-strain law, whose evolution is driven by a nonlocal strain measure. A 3D finite element formulation is used. Bridge natural frequencies and modal shapes are evaluated and compared with experimental results. Then, the nonlinear step-by-step dynamic analysis of the entire bridge and an equivalent pier is performed, considering a set of natural earthquakes. The response of the bridge is analyzed in terms of top displacement, acceleration and damage patterns.
\end{abstract}

Keywords: Masonry bridge, Damage, Finite Element analysis, Seismic behavior, Nonlinear dynamic response.

\section{Introduction}

Masonry structures form a large part of the Italian historical and architectural heritage. In particular, masonry arch bridges, most of them being ancient constructions, are still used today in rail and road networks. Considering the high seismic risk of the Italian country, especially regarding masonry structures, as shown, for instance, by the recent seismic events $[33,34]$, the seismic assessment of their safety conditions is a relevant issue. In particular, the existing masonry bridges, widely spread in South of Europe, are characterized by high vulnerability. Hence, their assessment and the development of risk mitigation strategies represent very important and challenging tasks [13]. These considerations motivate the interest in developing accurate and efficient numerical tools to study structural response of masonry arch bridges. Several numerical procedures have been proposed based on different modeling approaches. A comprehensive review can be found in [29]. Limiting the attention to the approaches based on the Finite Element (FE) method, a wide variety of models has been developed ranging from simplified 1D formulations to more sophisticated full 3D methods. Although some of them assume a linear elastic constitutive law for masonry, it is essential to introduce the nonlinear mechanisms characterizing masonry behavior to obtain a realistic 
description of the structural response under seismic actions. These are mainly related to the formation, propagation and coalescence of brittle microcracks and to friction slidings occurring in mortar joints. Accordingly, constitutive relationships formulated on the basis of continuum damage mechanics and plasticity models are usually adopted.

A suitable criterion for classifying models proposed for masonry is related to the modeling scale. Micromechanical formulations describe in details masonry microstructure, distinguishing between blocks/bricks, mortar and interfaces $[4,17]$. All the details about the geometrical arrangement of the constituents are accurately described, as well as their constitutive behavior. Although very reliable in reproducing the response of masonry structures, this approach requires very high computational costs. Therefore, it is usually applied to study the response of small structural elements. Conversely, to investigate the overall mechanical behavior of real-scale structures, macromechanical approaches are more conveniently adopted $[2,8,18,22]$. These describe masonry as an equivalent homogeneous medium. Thus, as the FE discretization is not conditioned by the actual geometry and arrangement of masonry constituents, the required computational effort is considerably lower. The main drawback is related to the identification of the macroscopic constitutive relationship and evaluation of the mechanical parameters. Usually, these are determined on the basis of laboratory tests on small assemblages of the masonry constituents. A good compromise between micro and macro approaches is represented by multi-scale procedures based on homogenization techniques [5, 25]. In this framework, an equivalent homogeneous continuum is adopted at the structural level. The constitutive response at each macroscopic point is derived by analyzing a representative volume element, properly selected to take into account all the information about masonry microstructure. Herein, the interest is focused on the macroscopic approach applied to the analysis of masonry bridges. In this framework, Fanning and Boothby in [15] adopted a 3D FE model based on a smeared crack model to reproduce the onset of cracks in the zones undergoing tensile stresses. Domede et al. [14] analyzed the structural behavior of a multi-span railway masonry bridge by using a 3D anisotropic damage model, describing opening and re-closure of the cracks and evaluating macroscopic parameters by means of a homogenization technique. Pelà et al. [27] compared nonlinear static and dynamic analyses for the seismic assessment of masonry bridges, using a $3 \mathrm{D}$ FE formulation and an elastic-plastic model based on the Drucker-Prager isotropic criterion.

This study investigates the effects of damaging mechanisms on the dynamic response of 'Ponte delle Torri' in Spoleto. To analyze the degrading behavior and the modification of the dynamic response due to damage evolution under seismic actions, a 3D FE formulation based on a macroscopic approach is adopted. The nonlinear dynamic response of the same 
structure was already investigated in [30] by using the concrete damage plasticity model available in Abaqus software formulated for isotropic damaging materials.

Anisotropic constitutive laws should be rigorously adopted for masonry with regular fabric, as these would be more accurate in describing the damaging mechanisms of brittle-like materials $[9,20]$. However, for ancient constructions, where material mechanical properties and arrangement are affected by strong uncertainty, isotropic damage formulations can be suitably and prudentially used [2, 27, 36]. These allow to satisfactorily capture the main effects of microcracks onset and propagation on the overall response, without requiring a large number of mechanical parameters, which can be hardly identified for ancient constructions. Moreover, anisotropy of material behavior is reproduced even by isotropic damage models by development and subsequent localization of damage. In [16] issues concerning the adoption of isotropic and anisotropic damage modeling are discussed. This study adopts the isotropic damage model presented in [4], introducing a scalar damage variable in the stress-strain constitutive relationship.

Damage evolution is governed by a strain measure defined on the basis of the principal strains, assuming that formation and evolution of microcracks is mainly driven by tensile strains [26]. To avoid mesh-dependency of the FE solution, due to the presence of strainsoftening in the adopted constitutive law, a nonlocal integral regularization technique is employed [28]. The 3D FE formulation proposed in [4] is here modified to perform dynamic analyses. First, modal analysis of the overall bridge is performed and the results obtained by the $3 \mathrm{D}$ FE model are compared with those derived by ambient vibration tests. Then, the nonlinear dynamic response of the overall bridge and of a single pier, whose size is chosen to approximately reproduce the out-of-plane dynamic characteristic of the overall bridge, is evaluated. A set of seven natural earthquake records are properly selected so as to match the defined design spectra, according to the Italian Building Code [1] and considering three return periods. In Sections 2 and 5 a brief description of the bridge structural features and constructive history, along with the seismic history and seismic hazard of the site, is given. Then, Sections 3 and 4 introduce the damage model and the FE formulation. Finally, section 6 contains the results of the numerical investigations performed on the bridge. Concluding remarks are given in the last Section.

\section{Structural description and historical background}

'Ponte delle Torri' is one of the most prominent monuments of the Municipality of Spoleto, connecting Sant'Elia hill, where the city lies, with Monteluco (Figure 1). It is a masonry 
bridge consisting of the abutments and nine piers ("Torri"), linked at their top by pointed arches. The bridge has total length $196.79 \mathrm{~m}$ and the piers a variable height, the tallest being over $70 \mathrm{~m}$ high (Figure 2). The thickness is $5.10 \mathrm{~m}$ at the deck level and $1.70 \mathrm{~m}$ at the 'Muraglione' on the top. All the piers are hollow, with wall thickness $1.70 \mathrm{~m}$. On the side of Sant'Elia hill the span length ranges between $7.00 \mathrm{~m}$ and $10.00 \mathrm{~m}$, including the two central largest spans. On the side of Monteluco the span length is constant and equal to 5.00 $\mathrm{m}$, and the piers are more homogeneous, with length ranging between $9.00 \mathrm{~m}$ and $11.50 \mathrm{~m}$. The abutments have length 16.50 (Sant'Elia hill) and $17.15 \mathrm{~m}$ (Monteluco). The piles are founded on emerging rock [10]. The present configuration of the bridge, dating back to the early 13th century, is the result of several constructive phases over the centuries, as witnessed by the different geometric proportions of piers and arches [6, 32]. Romans built a smaller bridge aimed at carrying the water from Monteluco to the thermae of Spoleto. The base and the lower part of the piers on Monteluco side, in stonework with units coarsely dressed, is what remains of the Roman bridge. The upper part of these piers, similarly to most piers on the side of Sant'Elia hill, are in stonework with dressed units and sharp corners [19]. It can be presumed that the arches at intermediate height between piers 2, 3 and 4, as well as the flying buttress between piers 4 and 5, were built during the same constructive phase. The last works in the Middle Age were accomplished under Cardinal Albornoz. In the subsequent centuries, the bridge underwent many interventions of strengthening and restoration [32]. At present, the bridge shows a diffuse state of cracking, localized cracks in some arches and a sub-vertical crack in the West elevation of pier 4 [19].

\section{Damage model}

To describe the onset and propagation of microfractures in masonry material, an isotropic damage model is introduced. This, presented in [4] to describe the response of the bricks in a micromechanical framework, is here generalized to reproduce the degrading behavior of the masonry material, regarded as an equivalent homogenized continuum [2, 8, 18]. The stress-strain relationship is written as:

$$
\boldsymbol{\sigma}=(1-D) \mathbf{E} \boldsymbol{\varepsilon}
$$

where $\varepsilon=\left[\varepsilon_{x}, \varepsilon_{y}, \varepsilon_{z}, \gamma_{x y}, \gamma_{y z}, \gamma_{z x}\right]^{T}$ and $\boldsymbol{\sigma}=\left[\sigma_{x}, \sigma_{y}, \sigma_{z}, \tau_{x y}, \tau_{y z}, \tau_{z x}\right]^{T}$ are the strain and stress vectors, respectively, and $\mathbf{E}$ is the $6 \times 6$ isotropic elastic constitutive matrix of the undamaged material. The scalar damage variable $D$ is introduced, equally affecting all the 


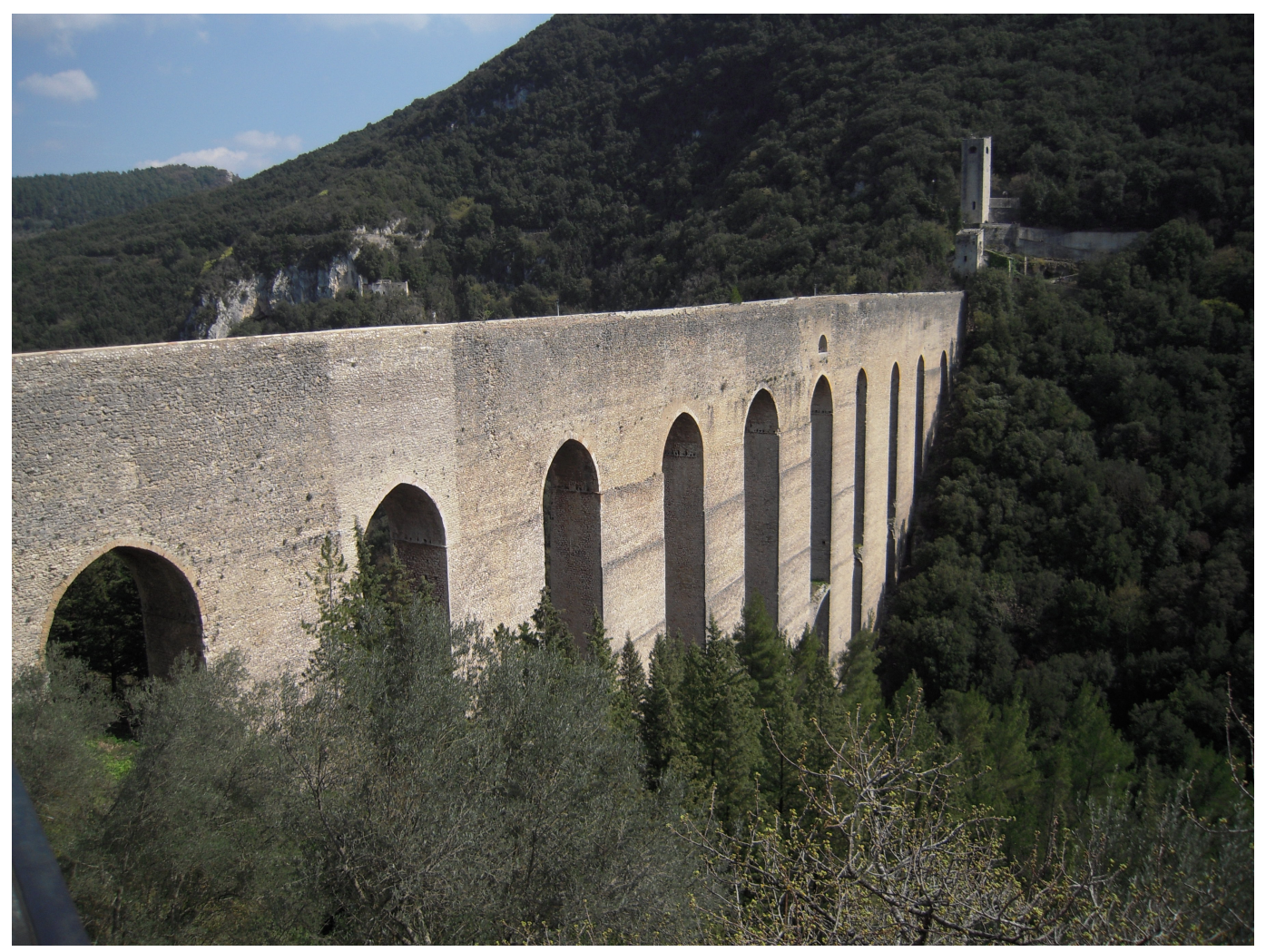

Figure 1: View of 'Ponte delle Torri' from Sant'Elia hill.

components of the matrix $\mathbf{E}$, and leading to the definition of an effective constitutive matrix in the form $\widetilde{\mathbf{E}}=(1-D) \mathbf{E}$, which contains the degraded constitutive coefficients. The variable $D$ varies in the range $[0,1]$, the bound values denoting initial virgin state and completely damaged state of the material, respectively. Moreover, the thermodynamics irreversibility condition is enforced, that is $\dot{D} \geq 0$.

A damage associated variable, driving its evolution, is defined as the following equivalent strain measure:

$$
\varepsilon_{e q}=\sqrt{\left\langle\sum_{i=1}^{3}\left\langle\varepsilon_{i}+\varepsilon_{o}\right\rangle_{+}^{2}-\kappa \sum_{i=1}^{3} \sum_{j=1}^{3} \frac{\left(1-\delta_{i j}\right)}{2}\left\langle\varepsilon_{i}\right\rangle_{-}\left\langle\varepsilon_{j}\right\rangle_{-}\right\rangle_{+}}-\varepsilon_{o}
$$

where $\varepsilon_{i / j}$ are the principal strains, $\kappa$ is a material parameter controlling the reduction of the equivalent tensile strain due to the presence of compressive strains and $\varepsilon_{o}$ is a regularization factor ensuring the convexity of the limit domain. The brackets $\langle\bullet\rangle_{+/-}$extract the positive/negative part of the variable and $\delta_{i j}$ is the Kronecker's symbol.

As a consequence of the strain-softening behavior characterizing masonry material response, 


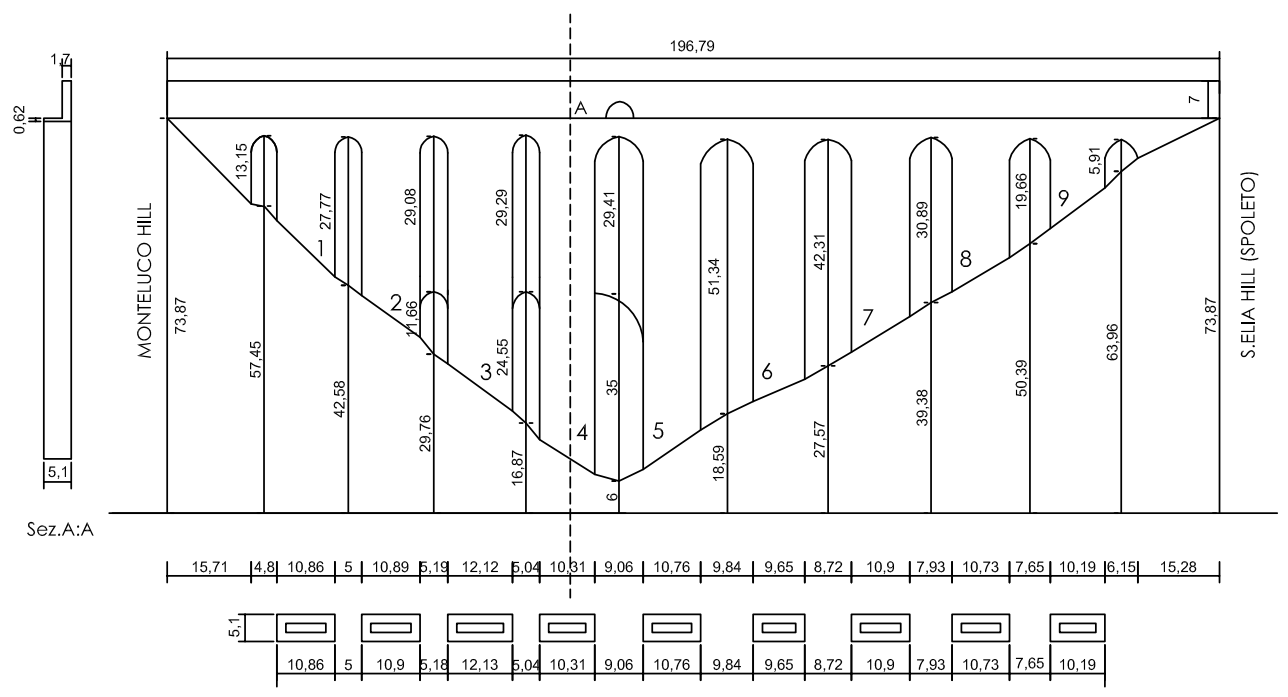

Figure 2: 'Ponte delle Torri', longitudinal section of the bridge from North.

localization of strains and damage can occur. As known, this leads to numerical drawbacks, that is mesh-dependency of the results, when a finite element solution procedure is adopted. To overcome these problems, several regularization techniques have been proposed. Among them, the nonlocal integral procedure has been widely and efficiently adopted [7, 28]. Therefore, the nonlocal definition of the equivalent strain in (2) is introduced as:

$$
\bar{\varepsilon}_{e q}(\mathbf{x})=\frac{1}{\int_{\Omega_{r}} \psi(\mathbf{y}) d V} \int_{\Omega_{r}} \psi(\mathbf{x}-\mathbf{y}) \varepsilon_{e q}(\mathbf{y}) d V
$$

where $\Omega_{r}$ and $\psi$ denote the reference volume and the weighting function. The latter measures the influence on the analyzed point $\mathbf{x}$ of the generic point $\mathbf{y}$, lying in its neighborhood $\Omega_{r}$, given by:

$$
\psi(\mathbf{x}-\mathbf{y})=e^{-\left(\frac{\|\mathbf{x}-\mathbf{y}\|}{l_{c}}\right)^{2}}
$$

where $l_{c}$ is the material characteristic length, set on the basis of the microstructure size. Then, the defined nonlocal equivalent strain measure is introduced in an exponential law to rule the evolution of damage in the masonry material. This is expressed as:

$$
\widetilde{D}=1+\frac{1}{\bar{\varepsilon}_{e q}\left(\varepsilon_{t}-\varepsilon_{u}\right)^{3}} e^{-\beta\left(\bar{\varepsilon}_{e q}-\varepsilon_{t}\right)}\left(\bar{\varepsilon}_{e q}-\varepsilon_{u}\right)^{2}\left(\bar{\varepsilon}_{e q} \varepsilon_{u}+\bar{\varepsilon}_{e q} \varepsilon_{t}-2 \varepsilon_{t}^{2}\right)
$$

where $\varepsilon_{t}$ is the tensile strain threshold, $\varepsilon_{u}$ the ultimate value of the equivalent strain corresponding to the full damage and $\beta$ a parameter governing the softening branch of the 


\begin{tabular}{|c|c|c|c|c|c|c|c|c|}
\hline$E[\mathrm{MPa}]$ & $\nu$ & $\varepsilon_{t}$ & $\kappa$ & $\varepsilon_{u}$ & $\varepsilon_{0}$ & $\beta_{t}$ & $\beta_{c}$ & $\alpha$ \\
\hline 8000 & 0.2 & $0.25 \times 10^{-4}$ & 0.03 & $15 \times 10^{-4}$ & $1 \times 10^{-5}$ & 14000 & 200 & 8000 \\
\hline
\end{tabular}

Table 1: 'Ponte delle Torri': material parameters adopted for the numerical model.

stress-strain relationship, set as:

$$
\beta=\beta_{t}+\frac{1}{1+\exp \left(\alpha\left(I_{1}-I_{1 m}\right)\right)}\left(\beta_{c}-\beta_{t}\right)
$$

with $\beta_{c}$ and $\beta_{t}$ the values for a mostly contracted or elongated strain state, respectively, $\alpha$ governing the rate of the variation of $\beta$ from $\beta_{c}$ to $\beta_{t}$ and vice-versa, $I_{1}$ the value of the strain first invariant and $I_{1 m}$ its value corresponding to $\beta=\left(\beta_{c}+\beta_{t}\right) / 2$. Finally, the current damage value is evaluated as:

$$
D=\max _{\text {history }}\{0, \min \{\widetilde{D}, 1\}\}
$$

Figure 3 contains the stress-strain law corresponding to the material parameters in Table 1. A detailed description of the role of the material parameters and their identification procedure can be found in [3].

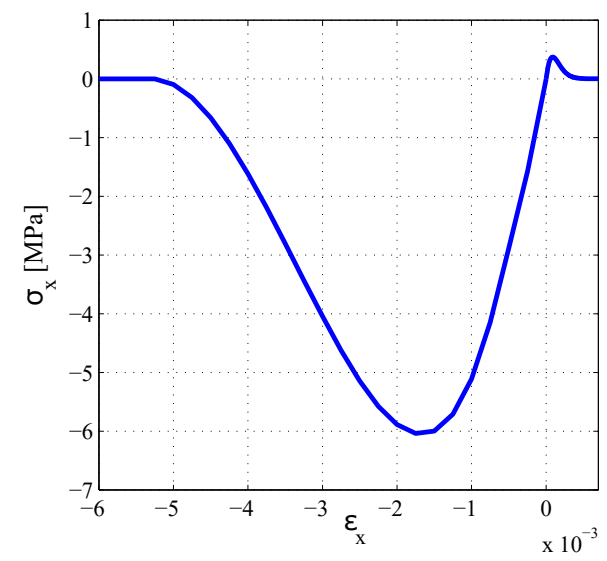

Figure 3: Masonry uni-axial stress-strain law.

\section{Finite element formulation and solution algorithm}

A finite element (FE) numerical procedure, based on the damage model presented in Section 3 , is formulated and implemented in the FE code FEAP [35] to perform nonlinear dynamic 
analyses. A displacement-based 8-node brick element is developed with three degrees of freedom at each node $k$, i.e. the displacement parameters $u_{k}, v_{k}$ and $w_{k}$, interpolating the displacement field $u(x, y, z), v(x, y, z)$ and $w(x, y, z)$ through tri-linear shape functions. The Gauss integration technique is used to evaluate element matrices and vectors, by adopting a $2 \times 2 \times 2$ rule.

The global equilibrium equations, governing the FE solution procedure, are expressed as:

$$
\mathbf{M} \ddot{\mathbf{U}}+\mathbf{C} \dot{\mathbf{U}}+\mathbf{P}(\mathbf{U})=\mathbf{F}
$$

where $\mathbf{U}, \dot{\mathbf{U}}$ and $\ddot{\mathbf{U}}$ are the global vectors collecting the nodal displacement, velocity and acceleration parameters, $\mathbf{M}$ and $\mathbf{C}$ are the mass and damping global matrices, $\mathbf{P}$ and $\mathbf{F}$ denote the vector of the internal resisting forces and external loads, respectively.

To solve Equations (8) the Newmark implicit time integration scheme is adopted with coefficients $\gamma=1 / 2$ and $\beta=1 / 4$. The solution of the nonlinear problem at each time step $\Delta t$ is evaluated by using the Newton-Raphson iterative algorithm. Therefore, at each NewtonRaphson iteration ' $i$ ', the current global tangent stiffness matrix and residual vector have to be computed. This requires the evaluation of the tangent stiffness matrix and residual vector at the element level. Herein, for the sake of simplicity, the secant element stiffness matrix is computed and assembled to obtain the global stiffness matrix used for the Newton-Raphson iterations, defined as:

$$
\mathbf{K}^{e, i}=\int_{\Omega^{e}} \mathbf{B}^{e T}\left(1-D^{i}\right) \mathbf{E B}^{e} d \Omega^{e}
$$

where the superscript ' $i$ ' denotes the current global iteration, $\mathbf{B}^{e}=\mathbf{L} \mathbf{N}^{e}$ is the matrix obtained by applying the 3D compatibility operator $\mathbf{L}$ to the shape function matrix $\mathbf{N}^{e}$ and $\Omega^{e}$ is the element volume. The element internal force vector is defined as:

$$
\mathbf{P}^{e, i}=\int_{\Omega^{e}} \mathbf{B}^{e T} \boldsymbol{\sigma}^{i} d \Omega^{e}=\int_{\Omega^{e}} \mathbf{B}^{e T}\left(1-D^{i}\right) \mathbf{E} \varepsilon^{i} d \Omega^{e}
$$

Hence, at each global iteration ' $i$ ', the current value of the damage variable $D^{i}$ has to be evaluated by solving the evolution problem governed by Equation (5) and (7).

A consistent approach is used to define the element mass matrix as:

$$
\mathbf{M}^{e}=\int_{\Omega^{e}} \mathbf{N}^{e T} \rho \mathbf{N}^{e} d \Omega^{e}
$$


where $\rho$ denotes the material density mass and the superscript $i$ is omitted, as the mass matrix is constant. The element damping matrix $\mathbf{C}^{e}$ is defined using the Rayleigh approach, so as to get a damping factor equal to $5 \%$ on the first two vibration modes. Finally, the external force vector accounts for all the external applied loads, both distributed and concentrated at nodes.

An energy convergence test is performed at each Newton-Raphson iteration. If the test is satisfied, the iterative procedure is stopped. Once the solution at time $t_{n}$ is determined, the solution at $t_{n+1}=t_{n}+\Delta t$ can be evaluated.

\section{Seismic history and current seismic zonation}

Italy is one of the countries with the richest macroseismic observations catalogues. Using the most up-to-date [21], starting from 1000 AD, for the town of Spoleto it is possible to find a first list of 36 observations, whose locally felt intensity is above the damage threshold $\left(I_{s}\right.$ $\geq \mathrm{V}$ Mercalli-Cancani-Sieberg, MCS). However, it may be expected that earthquakes felt in the area are more numerous than these. Such a limited number is due to the fact that the historical evidence related to earthquakes is not always still existent, or has been located or has been studied. In such cases it is useful to exploit an attenuation law to get felt intensities from known epicentral ones. In this case, the law defined by Decanini and Mollaioli [12] has been applied to a catalogue of epicentral intensities [31], and again only felt intensities greater than or equal to V MCS has been retained. A total (observed and calculated) list of 80 events has been reconstructed. The list of the earthquakes with MCS intensity at the site $I_{s} \geq$ VII is reported in Table 2, consisting of 21 earthquakes, five of which with epicentre in the Spoleto area. The maximum intensities at the site are $I_{s}=\mathrm{IX}-\mathrm{X}$, recorded in 1328 , and $I_{s}=\mathrm{IX}$ in 1730. Among the recent seismic events, it is worthwhile to quote the 1979 Valnerina earthquake, the 2009 L'Aquila earthquake and the seismic swarm of Appennino umbro-marchigiano in 1997 (Table 3) [21, 23, 24].

The expected maximum horizontal ground acceleration $a_{g}$ specified by the Italian Building Code for the site and type A soil [1] is reported in Figure 4 as function of the return period TR. In particular, $a_{g}=0.217 \mathrm{~g}$ for $\mathrm{TR}=475$ years, which is classified as medium seismicity. 


\begin{tabular}{|c|c|c|c|c|}
\hline $\begin{array}{c}\text { Date } \\
\text { Time UTC }\end{array}$ & Earthquake & $\begin{array}{c}\text { Epicentral } \\
\text { Intensity } \\
I_{o}\end{array}$ & $\begin{array}{c}\text { Intensity } \\
\text { at the site } \\
I_{s}\end{array}$ & $M_{w}$ \\
\hline 1246 & Spoleto & VII-VIII & VII-VIII & $5.35 \pm 0.34$ \\
\hline 1277 & Spoleto & VIII & VIII & $5.57 \pm 0.34$ \\
\hline 1279-04-30 & Appennino umbro-marchigiano & IX & VII & $6.31 \pm 0.33$ \\
\hline $1298-12-01$ & Reatino & IX-X & VIII & $6.20 \pm 0.34$ \\
\hline 1328-12-01 & Valnerina & $\mathrm{X}$ & IX-X & $6.38 \pm 0.41$ \\
\hline $\begin{array}{c}1461-11-27 \\
21: 05\end{array}$ & L'Aquila & $\mathrm{X}$ & VII & $6.41 \pm 0.34$ \\
\hline $\begin{array}{c}1599-11-06 \\
01: 25\end{array}$ & Valnerina & IX & VIII & $5.99 \pm 0.32$ \\
\hline 1646-04-28 & Monti della Laga & IX & VII-VIII & 5.90 \\
\hline 1667 & Spoleto & VII & VII & $5.14 \pm 0.34$ \\
\hline $\begin{array}{c}\text { 1703-01-04 } \\
18: 00\end{array}$ & Appennino umbro-reatino & $\mathrm{XI}$ & VII-VIII & $6.74 \pm 0.11$ \\
\hline $\begin{array}{c}1703-01-16 \\
13: 30\end{array}$ & Appennino umbro-reatino & - & VIII & - \\
\hline $\begin{array}{c}\text { 1703-02-02 } \\
11: 05\end{array}$ & L’Aquila & $\mathrm{X}$ & VIII & $6.72 \pm 0.17$ \\
\hline $\begin{array}{c}1719-06-27 \\
06: 30\end{array}$ & Valnerina & VIII & VIII & $5.53 \pm 0.31$ \\
\hline $1730-05-12$ & Valnerina & IX & IX & $5.92 \pm 0.16$ \\
\hline 1745-03 & Spoleto & VII & VIII & $5.14 \pm 0.34$ \\
\hline 1751-07-27 & Appennino umbro-marchigiano & $\mathrm{X}$ & VII & $6.25 \pm 0.22$ \\
\hline $\begin{array}{c}1767-06-05 \\
01: 30\end{array}$ & Spoletino & VII-VIII & VII-VIII & $5.44 \pm 0.60$ \\
\hline 1815-09-03 & Valnerina & VIII & VII & $5.45 \pm 0.30$ \\
\hline $1832-01-13$ & Valle del Topino & $\mathrm{X}$ & VII & $6.33 \pm 0.14$ \\
\hline $1859-08-22$ & Valnerina & VIII-IX & VIII-IX & $5.53 \pm 0.32$ \\
\hline $\begin{array}{c}1879-02-23 \\
18: 30\end{array}$ & Valnerina & VIII & VIII & $5.57 \pm 0.37$ \\
\hline
\end{tabular}

Table 2: List of earthquakes with $I_{s} \geq$ VII. 


\begin{tabular}{|c|c|c|c|c|c|c|}
\hline $\begin{array}{c}\text { Date } \\
\text { Time UTC }\end{array}$ & Earthquake & $\begin{array}{c}\text { Epicentral } \\
\text { Intensity } \\
I_{O}\end{array}$ & $\begin{array}{c}\text { Intensity } \\
\text { at the site } \\
I_{s}\end{array}$ & Depth $[\mathrm{km}]$ & $M_{w}$ & $\begin{array}{l}\text { Style of } \\
\text { faulting }\end{array}$ \\
\hline $\begin{array}{l}\text { 1979-09-19 } \\
21: 35: 37\end{array}$ & Valnerina & VIII-IX & VI-VII & 6.0 & $5.86 \pm 0.09$ & Normal \\
\hline $\begin{array}{l}1980-02-28 \\
21: 04: 40\end{array}$ & Valnerina & VI & VI & 12.0 & $5.00 \pm 0.09$ & Strike-slip \\
\hline $\begin{array}{l}\text { 1980-05-24 } \\
20: 16: 06\end{array}$ & Valnerina & V-VI & V-VI & 15.0 & $4.62 \pm 0.19$ & - \\
\hline $\begin{array}{l}1997-05-12 \\
13: 50: 15\end{array}$ & $\begin{array}{l}\text { Massa } \\
\text { Martana }\end{array}$ & $\overline{\mathrm{VI}}$ & $\overline{\mathrm{V}}$ & - & $4.79 \pm 0.17$ & - \\
\hline $\begin{array}{l}1997-09-26 \\
00: 33: 13\end{array}$ & $\begin{array}{l}\text { Appennino } \\
\text { umbro- } \\
\text { marchigiano }\end{array}$ & - & VI & 5.7 & $5.70 \pm 0.09$ & Strike-slip \\
\hline $\begin{array}{l}\text { 1997-09-26 } \\
09: 40: 27\end{array}$ & $\begin{array}{l}\text { Appennino } \\
\text { umbro- } \\
\text { marchigiano }\end{array}$ & VIII-IX & VI & 5.7 & $6.01 \pm 0.09$ & Strike-slip \\
\hline $\begin{array}{l}\text { 1997-10-03 } \\
08: 55: 22\end{array}$ & $\begin{array}{l}\text { Appennino } \\
\text { umbro- } \\
\text { marchigiano }\end{array}$ & - & V-VI & 4.8 & $5.25 \pm 0.09$ & Normal \\
\hline $\begin{array}{l}\text { 1997-10-14 } \\
15: 23: 11\end{array}$ & $\begin{array}{l}\text { Appennino } \\
\text { umbro- } \\
\text { marchigiano }\end{array}$ & VII-VIII & $\mathrm{V}$ & 6.0 & $5.65 \pm 0.09$ & Strike-slip \\
\hline $\begin{array}{l}2005-12-15 \\
13: 28: 39\end{array}$ & $\begin{array}{l}\text { Valle del } \\
\text { Topino }\end{array}$ & V-VI & $\mathrm{V}$ & 18.4 & $4.66 \pm 0.09$ & Normal \\
\hline $\begin{array}{l}2009-04-06 \\
01: 32: 40\end{array}$ & L'Aquila & IX-X & VI-VII & 8.3 & $6.29 \pm 0.07$ & Normal \\
\hline
\end{tabular}

Table 3: List of recent earthquakes with $I_{s} \geq \mathrm{V}$. 


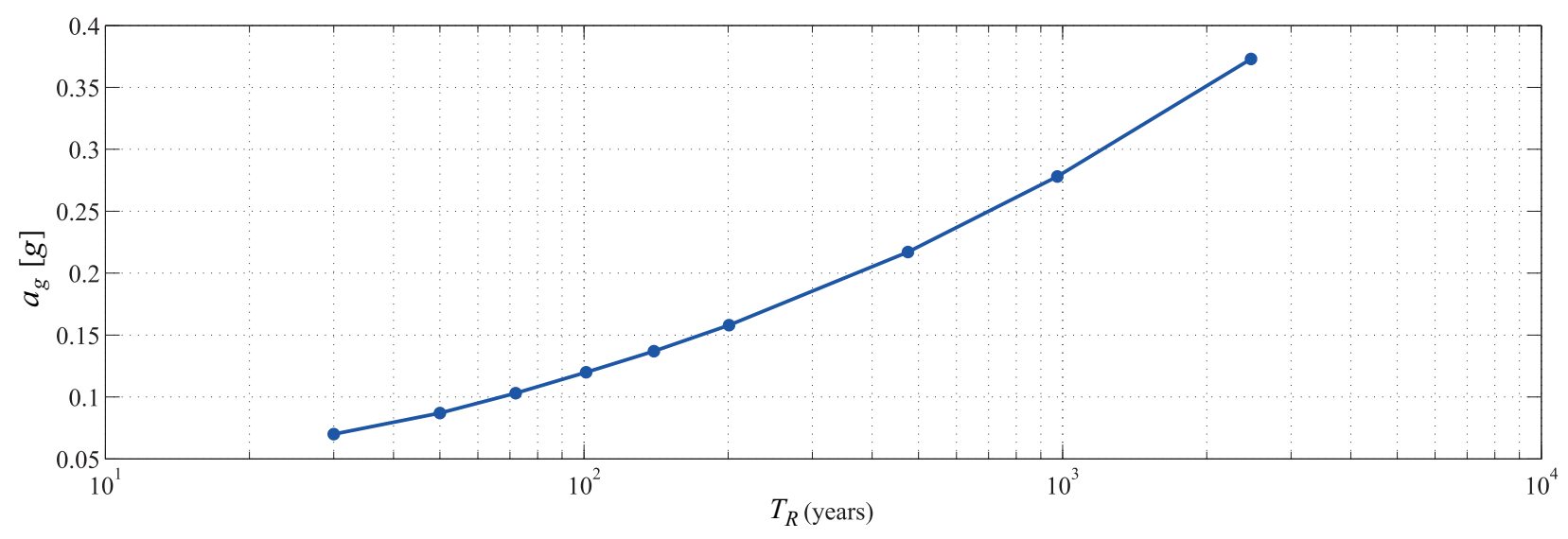

Figure 4: Expected maximum horizontal ground acceleration specified by the Italian Building Code for type A soil and different return periods.

\section{Dynamic response of 'Ponte delle Torri'}

In this section the dynamic behavior of 'Ponte delle Torri' is investigated by using the damage model and the FE formulation presented in Sections 3 and 4, respectively. The schematic of the bridge is shown in Figure 2, where the sizes of piers and deck are reported, as well as the number associated to each pier.

The mesh in Figure 5, made of 4042 3D brick FEs, is adopted, where the typical brick size is $2 \times 2 \times 2 \mathrm{~m}^{3}$ and the material parameters reported in Table 1 are set on the basis of the experimental data reported in [19]. The masonry tensile and compressive strengths are equal to $0.35 \mathrm{MPa}$ and $6.2 \mathrm{MPa}$, respectively, and the mass density $\rho$ is equal to $2067 \mathrm{~kg} \mathrm{~m}^{-3}$. The material characteristic length $l_{c}$ is set equal to $4.0 \mathrm{~m}$.

\subsection{Modal analysis}

First, modal analysis is performed and its results are compared with those obtained by the in-situ environmental experimental measures reported in [11]. This aims to validate the FE model in the linear elastic range. The first three frequencies $f_{i}$ and periods $T_{i}$ are contained in Table 4. The first row shows the values deduced by the ambient vibration tests, the second row those numerically evaluated via the adopted FE procedure. The difference is $4.6 \%$ for the first frequency, $1.8 \%$ for the second and $1.3 \%$ for the third, proving that the numerical model correctly reproduces geometry, boundary conditions and material elastic response. In Figure 5 the corresponding modal shapes are plotted, showing that the first three modes of the bridge are out-of-plane. 


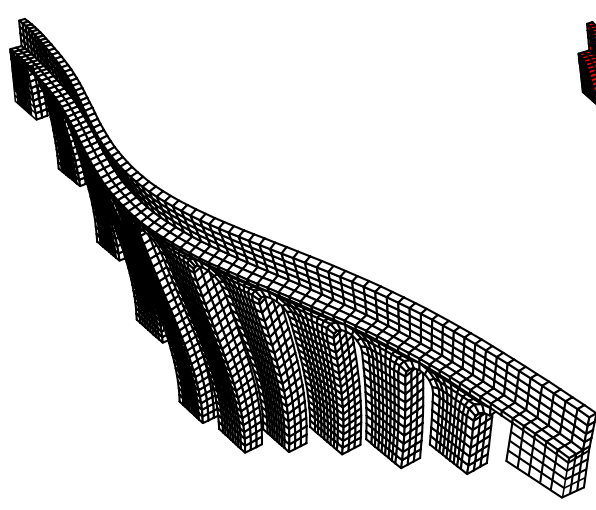

(a)

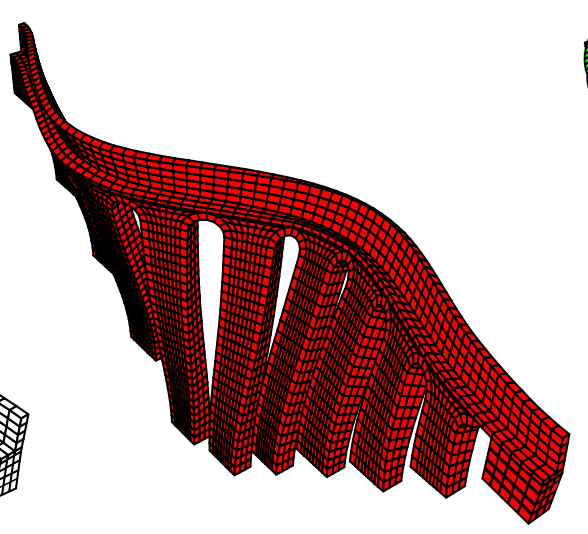

(b)

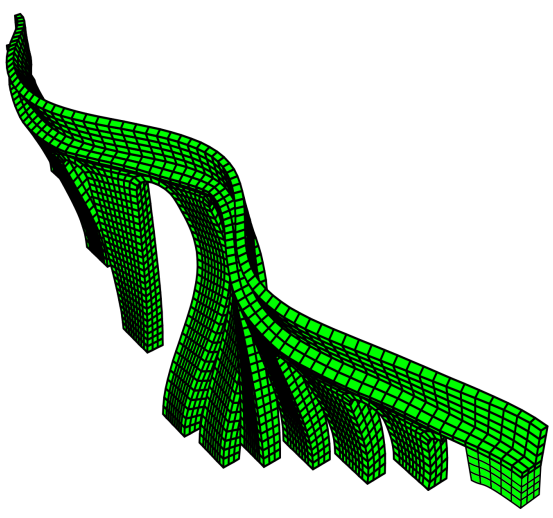

(c)

Figure 5: 'Ponte delle Torri': first three modal shapes corresponding to the frequencies and periods contained in the second row of Table 4: (a) Mode 1, (b) Mode 2, (c) Mode 3.

\begin{tabular}{|c|c|c|c|c|c|c|}
\hline & \multicolumn{2}{|c|}{ Mode 1 } & \multicolumn{2}{c|}{ Mode 2 } & \multicolumn{2}{c|}{ Mode 3 } \\
\hline & $f[\mathrm{~Hz}]$ & $T[\mathrm{~s}]$ & $f[\mathrm{~Hz}]$ & $T[\mathrm{~s}]$ & $f[\mathrm{~Hz}]$ & $T[\mathrm{~s}]$ \\
\hline Experimental & 0.634 & 1.577 & 1.021 & 0.979 & 1.508 & 0.663 \\
\hline 3D FE analysis & 0.605 & 1.652 & 1.039 & 0.962 & 1.489 & 0.671 \\
\hline
\end{tabular}

Table 4: 'Ponte delle Torri': first three experimentally (first row) and numerically (second row) evaluated natural frequencies and periods.

\subsection{Nonlinear dynamic analyses under natural earthquakes}

According to the Italian Building Code [1], nonlinear dynamic analyses can be performed under recorded accelerograms, provided that their choice is representative of the seismicity of the site, source mechanism, site conditions, magnitude, distance from the source, and maximum expected horizontal acceleration at the site. The recorded accelerograms shall be selected and scaled to match the response spectrum in the period range of interest. A set of seven natural earthquake records has been selected from [23, 24], with moment magnitude ranging between 4.3 and 6.5 , style of faulting either normal or strike-slip, recorded on type A soil at a distance ranging between 5.9 and $19.2 \mathrm{~km}$ from the epicentre (Table 5). The records have been scaled to match the spectral ordinates in the period range $0.5-2.5 \mathrm{~s}$. Three return periods have been considered in the analysis, namely 201, 475 and 975 years. The scaling factors for the selected accelerograms and the three return periods are reported in Table 6 .

In Figure 6, the elastic spectra of the selected records are shown, scaled by the factors reported in Table 6, along with the average spectra (red lines) and the elastic spectra according to the Italian Building Code [1] (blue lines). First, the dynamic response of the overall bridge is evaluated. The analysis is performed following two stages. In the first stage the bridge is 


\begin{tabular}{|c|c|c|c|c|c|}
\hline $\begin{array}{c}\text { Date } \\
\text { Time UTC }\end{array}$ & Earthquake & Municipality & Station & $\begin{array}{c}\text { Corrected } \\
\text { PGA } \\
{\left[\mathrm{cm} / \mathrm{s}^{2}\right]}\end{array}$ & $\begin{array}{c}\text { Distance } \\
\text { from the } \\
\text { epicentre } \\
\text { [km] }\end{array}$ \\
\hline $\begin{array}{c}2017-01-18 \\
09: 25: 42 \\
\end{array}$ & $\begin{array}{c}\text { Central } \\
\text { Italy }\end{array}$ & Amatrice & $\begin{array}{l}\text { Accumoli } \\
\text { (IT.ACC) }\end{array}$ & 101.544 & 16.7 \\
\hline $\begin{array}{c}2016-10-30 \\
06: 40: 18\end{array}$ & $\begin{array}{c}\text { Central } \\
\text { Italy }\end{array}$ & Norcia & $\begin{array}{c}\text { Montemonaco } \\
\text { (IT.MMO) }\end{array}$ & 185.324 & 19.2 \\
\hline $\begin{array}{c}2016-10-26 \\
19: 18: 06\end{array}$ & $\begin{array}{c}\text { Central } \\
\text { Italy }\end{array}$ & Ussita & $\begin{array}{c}\text { Castelluccio } \\
\text { di Norcia } \\
\text { (IT.CLO) }\end{array}$ & 215.128 & 10.8 \\
\hline $\begin{array}{c}2016-08-25 \\
03: 17: 16\end{array}$ & $\begin{array}{c}\text { Central } \\
\text { Italy }\end{array}$ & $\begin{array}{c}\text { Arquata } \\
\text { del Tronto }\end{array}$ & $\begin{array}{c}\text { Savelli } \\
\text { (IV.T1213) }\end{array}$ & 119.763 & 5.9 \\
\hline $\begin{array}{c}2009-04-07 \\
17: 47: 37\end{array}$ & L'Aquila & Fossa & $\begin{array}{c}\text { Rocca di } \\
\text { Mezzo } \\
\text { (IV.RM13) }\end{array}$ & 130.951 & 15.6 \\
\hline $\begin{array}{c}1998-09-09 \\
11: 28: 00\end{array}$ & $\begin{array}{c}\text { Appennino } \\
\text { lucano }\end{array}$ & $\begin{array}{l}\text { Laino } \\
\text { Borgo }\end{array}$ & $\begin{array}{c}\text { Lauria } \\
\text { (IT.LRS) }\end{array}$ & 161.928 & 18.0 \\
\hline $\begin{array}{c}\text { 1997-10-14 } \\
15: 23: 09\end{array}$ & $\begin{array}{c}\text { Appennino } \\
\text { umbro- } \\
\text { marchigiano }\end{array}$ & Foligno & $\begin{array}{c}\text { Cesi Monte } \\
\text { (CESM) }\end{array}$ & 175.507 & 8.7 \\
\hline
\end{tabular}

Table 5: Natural earthquake records selected for the analysis of 'Ponte delle Torri'.

\begin{tabular}{|c|c|c|c|}
\hline \multirow{2}{*}{ Record } & \multicolumn{3}{|c|}{ TR (years) } \\
\cline { 2 - 4 } & 201 & 475 & 975 \\
\hline Arquata del Tronto & 1.8791 & 2.5766 & 3.3521 \\
\hline Amatrice & 1.4351 & 1.9460 & 2.5320 \\
\hline L'Aquila & 1.7636 & 2.3998 & 3.1224 \\
\hline Laino Borgo & 0.6804 & 0.9244 & 1.2027 \\
\hline Cesi Monte & 1.1692 & 1.5850 & 2.0623 \\
\hline Ussita & 0.5849 & 0.7943 & 1.0334 \\
\hline Norcia & 0.5901 & 0.8011 & 1.0423 \\
\hline
\end{tabular}

Table 6: Scaling factors adopted for the considered seven records (first column), corresponding to a 201-years (second column), 475-years (third column) and 975-years (fourth column) return period. 

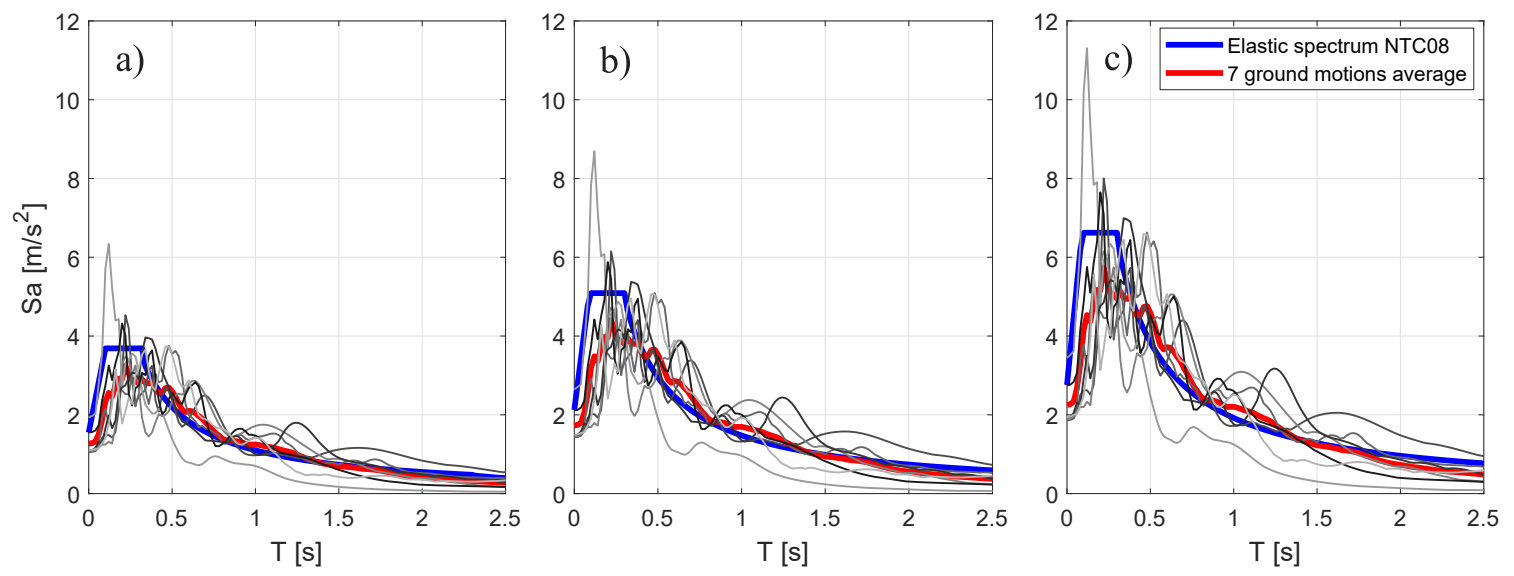

Figure 6: Elastic spectra of the selected records, their average spectra (red lines) and elastic spectra specified by the Italian Building Code [1] (blue lines) with scaling corresponding to return period: (a) 201-years, (b) 475- years and (c) 975- years.

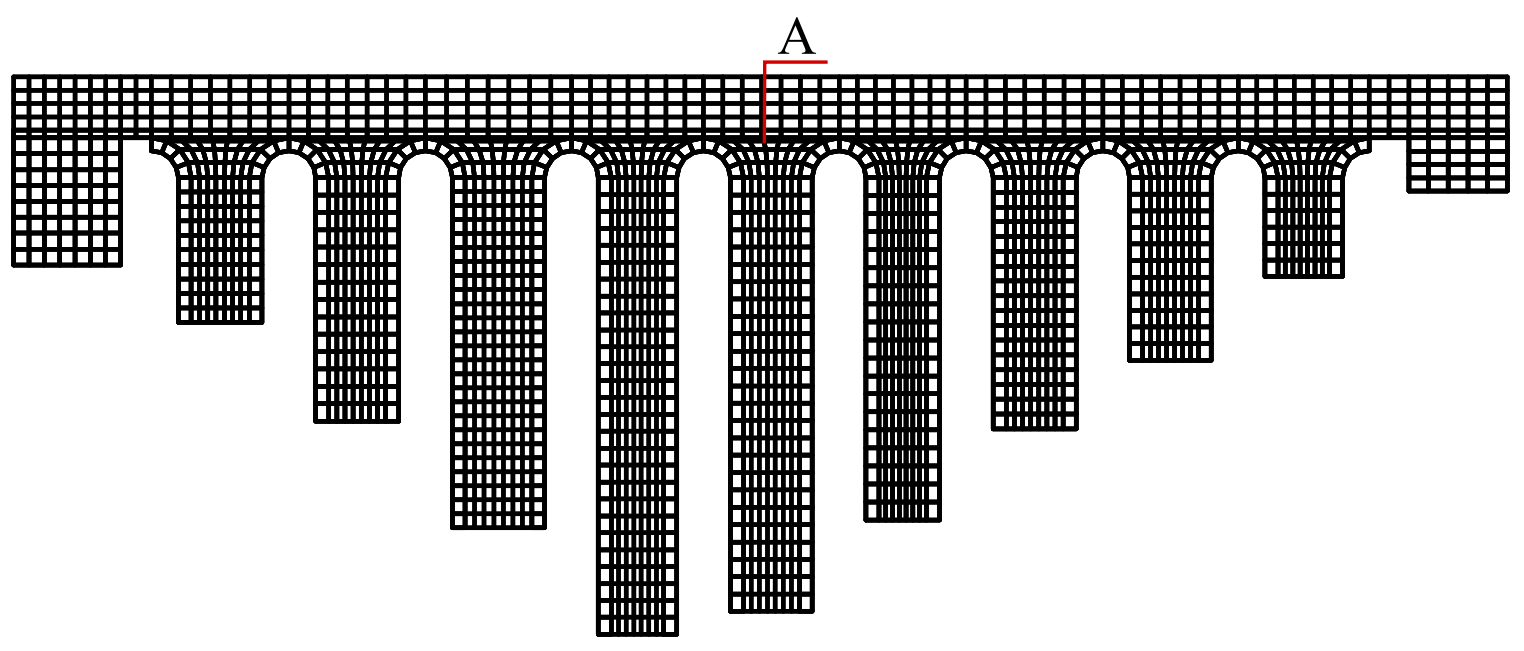

Figure 7: 'Ponte delle Torri': mesh longitudinal view.

subjected to the vertical loads due to self-weight. In the second stage the scaled recorded accelerations are applied, considering the E-W components applied along the bridge outof-plane direction. A time step $\Delta t$ equal to $0.0025 \mathrm{~s}$ is adopted for the analyses. The out-of-plane displacement and acceleration component at point A (see the mesh longitudinal view in Figure 7) is monitored together with the damage distribution.

To reduce the computational burden, a single pier is also modeled, whose geometric properties and boundary conditions are set so as to obtain information on the out-of-plane dynamic response of the overall bridge. Thus, the pier height is set equal to $48 \mathrm{~m}$, that is the average height of all the piers. Figure 8 shows (a) the schematic of the analyzed pier, and (b) the 


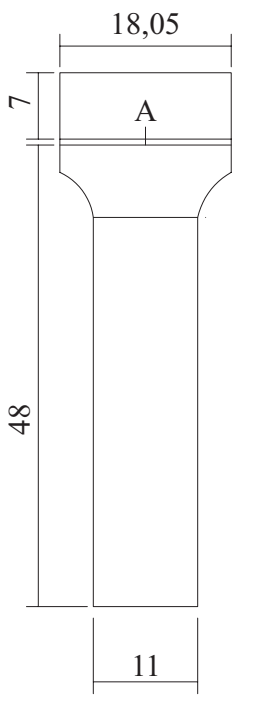

(a)

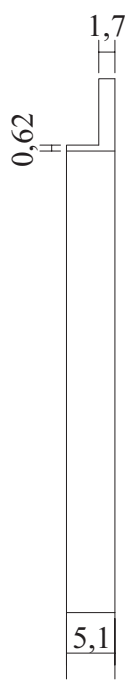

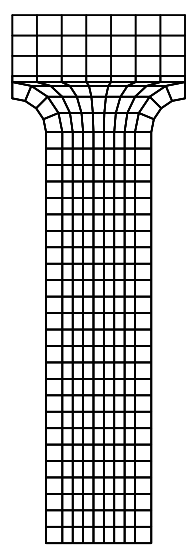

(b)

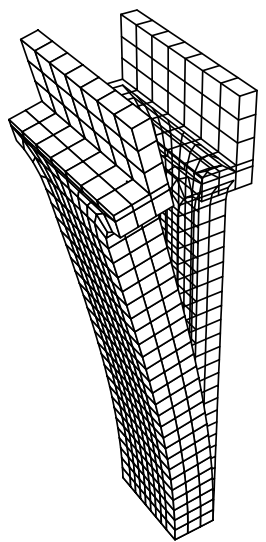

(c)

Figure 8: 'Ponte delle Torri': (a) schematic of the analyzed pier, (b) mesh longitudinal view, (c) undeformed and deformed mesh transverse view.

longitudinal and (c) transverse view of the FE model. A mesh made of 622 3D brick FEs is used. The nodes at the base are fully restrained, whereas the symmetry conditions are enforced on the nodes lying on the left and right vertical transverse planes, by restraining the translation component along the bridge longitudinal direction. The first natural frequency of the pier is equal to $0.603 \mathrm{~Hz}$, thus very close to that of the overall bridge $(0.605 \mathrm{~Hz})$.

Figures 9 to 15 show the dynamic response of the bridge in terms of (a) time history of the out-of-plane displacement component at point A (Figure 7) and (b) FFT (Fast-FourierTransform) of this, considering the selected records scaled according to the 475-years return period. In particular, the response obtained with the damage model presented in Section 5 (green lines) is compared with that evaluated by assuming an elastic constitutive behavior (blue lines), to highlight the effect of the damage evolution on the bridge dynamic behavior. Two main phenomena emerge: the damage onset and growth causes a reduction of the initial undamaged structural stiffness and this significantly modifies the bridge natural frequencies. At the same time, the displacements are amplified or reduced compared to the elastic case, depending on the frequency content of each record. In fact, the variation of the structural frequencies due to damage can definitely modify the bridge resonance conditions, as already outlined for other masonry structures [18]. In the cases of L'Aquila (Figure 11) and Ussita (Figure 14) earthquakes, the increase of the period of the structure causes a reduction of the seismic response. Conversely, the displacement amplification related to the decay of the structural stiffness becomes predominant for most of the other earthquakes (Figures 9, 10, 
12, 15). In the case of Cesi Monte record (Figure 13) the elastic and damaged responses are almost indistinguishable. The comparison of the FFT, computed for the out-of-plane displacement component time history at point $\mathrm{A}$ in the elastic and damaged case, shows that for the records causing a more severe degrading process in the bridge the frequency associated to the displacement maximum amplitude significantly decreases, that is the period elongation related to the damage is more evident. Again, it emerges that the displacement maximum amplitude can increase or decrease depending on the applied record. Figures 16, 17 and 18 show the time-histories of the out-of-plane acceleration evaluated at point A (Figure 7) exhibited by the bridge under the applied seven records for the 475-years return period. By comparing the elastic (blue lines) and damaged (green lines) response, it again emerges that the differences are more pronounced for the records causing a severe degrading process in the bridge. From figure 9 (c) to figure 15 (c) the time-history of the out-of-plane displacement at point $\mathrm{A}$ of the bridge (green lines) is compared with that of the equivalent single pier (red lines) in case of damaged response. To be noted is that the agreement between the two FE models is related to the frequency content of the applied record. However, for some of the selected records the results match very well, as for the cases of Arquata del Tronto, Amatrice and Cesi Monte records. When the frequency content of the applied earthquake is richer (see for example Figure 12 (b)), that is a larger range of the structural frequencies exhibit high displacement amplitudes, the match between the bridge and pier response is less satisfactory. Anyway, the analysis of the equivalent single pier can give relevant information about the global dynamic behavior of the bridge, with a significant saving of the computational costs. Thus, in the following the reduced model of the single pier is adopted to investigate the response under the complete set of records and for the three considered return periods. Figures 19-25 show the time history of the pier out-of-plane top displacement, measured at point A (Figure 8 (a)) for the selected records. The pier elastic response (blue lines) is compared with the damaged one (red lines). The same trends as for the entire bridge can be observed, as well as the points highlighted on the effect of the damaging process on the pier dynamic response still hold. Moreover, as expected, the higher the return period, the higher the effect of damage.

Finally, figures 26, 27 and 28 show the damage final distribution in the bridge for the three more severe records, i.e. L'Aquila, Laino Borgo and Norcia. The most damaged zones are located in corrispondence of the arches connecting the central piers, at the left abutment and at the central pier base. This satisfactorily match the damage survey of the bridge after the Central Italy 2016-2017 events reported in [30]. In figures 29, 30 and 31 the final damage distribution is also shown for the equivalent pier. In these cases damage localizes at the piers 
base, showing higher values on the left (North) side.

To better follow the progression of the degrading processes in the masonry bridge, a Global Damage Index $(G D I)$, measuring the overall damage state of the structure, is introduced as:

$$
G D I=\frac{1}{\int_{\Omega} d V} \int_{\Omega} D d V,
$$

only accounting in the integral for the region where $D \geq 0.1$.

The evolution of GDI in the equivalent pier is reported in Figure 32 for the three return periods. Figure 32 also shows that the damage evolution is very different depending on the applied excitation, being very sharp and rapid in some cases, namely Laino Borgo (green line), L'Aquila (blue line), Norcia (black line) and Ussita (grey line) earthquake records, more gradual for the others.

Tables 7, 8 and 9 contain the maximum displacement values experienced by the pier in the elastic (second column) and damaged (third column) case and their percentage difference (fourth column) for the seven records and the three considered return periods. For TR equal to 475-years the results evaluated analyzing the entire bridge are also shown, matching very well those computed for the equivalent pier. Figure 33 summarizes tables 7, 8, 9 with comparison of maximum dispacement for the elastic (blue bars) and damage (red bars) model. Finally, Table 10 contains the values of the monitored maximum local damage in the pier at the final step of the analysis for all the records and the three return periods. The maximum damage value is experienced by the structure under the Norcia record and reached after the first $12 \mathrm{~s}$ (Figure 32 (black line)). Figure 25 shows that in this case a significant amplification of the bridge top displacement occurs even for the lowest return period, with a maximum value which is doubled with respect to the elastic case. 


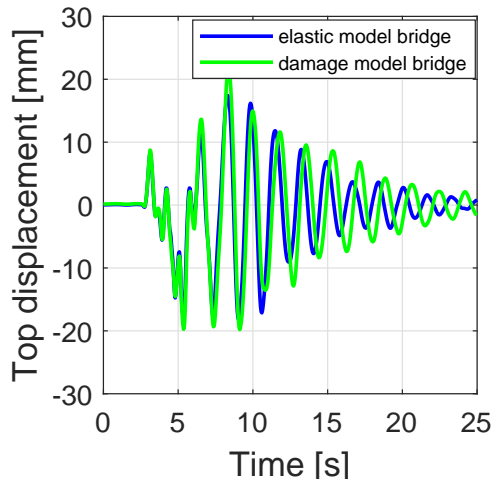

(a)

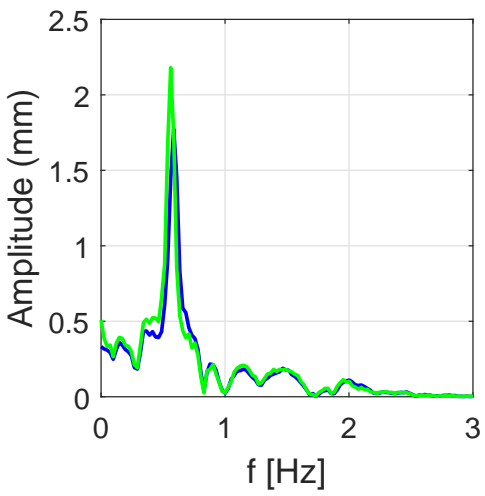

(b)

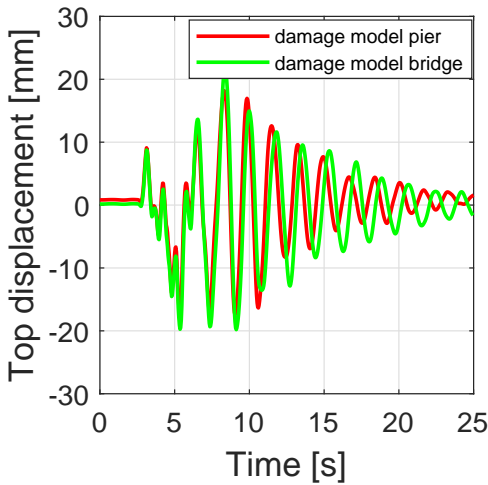

(c)

Figure 9: 'Ponte delle Torri': (a) out-of-plane displacement time-history at point A of the overall brigde for the elastic (blue line) and damage (green line) model under Arquata del Tronto record; (b) FFT of the out-of-plane displacement time-history in (a) for the elastic (blue line) and damage (green line) model; (c) comparison of the out-of-plane displacement time-history at point A for the overall bridge (green line) and the single pier (red line) in case of damaged response.

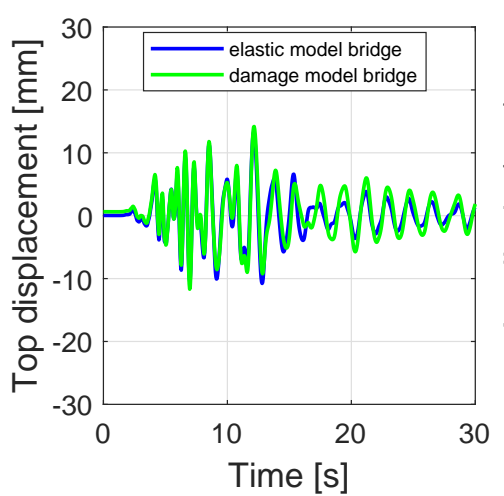

(a)

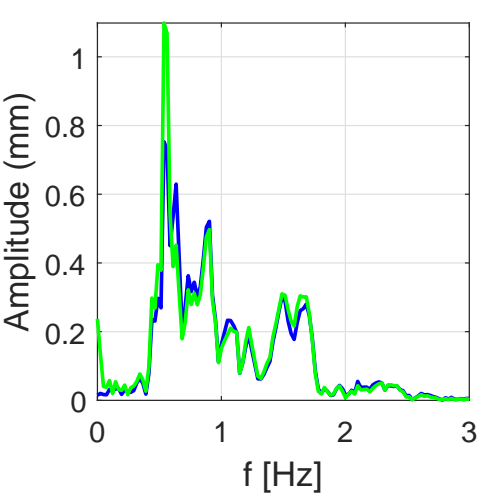

(b)

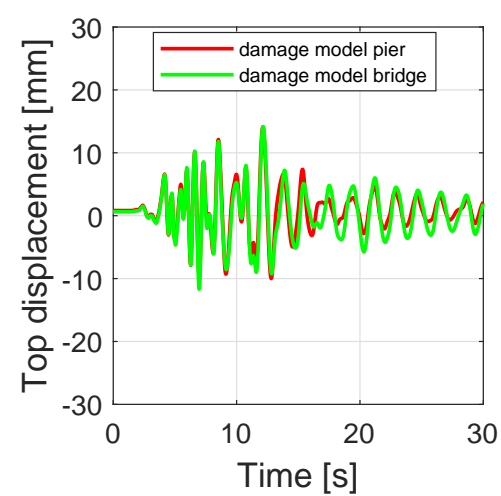

(c)

Figure 10: 'Ponte delle Torri': (a) out-of-plane displacement time-history at point A of the overall brigde for the elastic (blue line) and damage (green line) model under Amatrice record; (b) FFT of the out-of-plane displacement time-history in (a) for the elastic (blue line) and damage (green line) model; (c) comparison of the out-of-plane displacement time-history at point A for the overall bridge (green line) and the single pier (red line) in case of damaged response. 


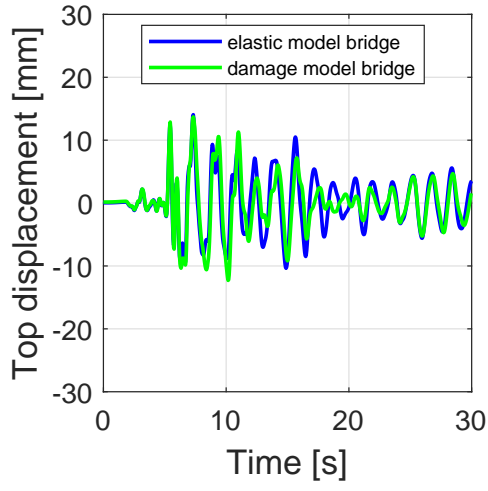

(a)

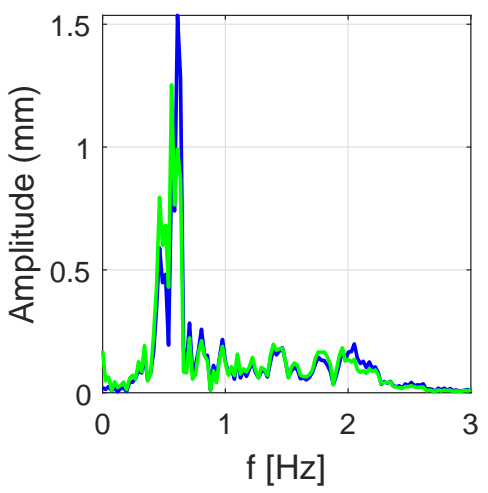

(b)

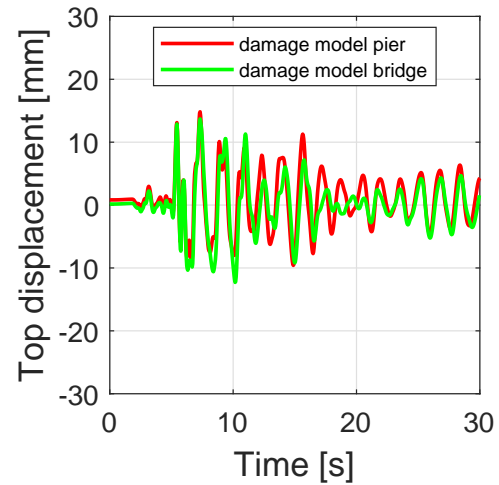

(c)

Figure 11: 'Ponte delle Torri': (a) out-of-plane displacement time-history at point A of the overall brigde for the elastic (blue line) and damage (green line) model under L'Aquila record; (b) FFT of the out-of-plane displacement time-history in (a) for the elastic (blue line) and damage (green line) model; (c) comparison of the out-of-plane displacement time-history at point A for the overall bridge (green line) and the single pier (red line) in case of damaged response.

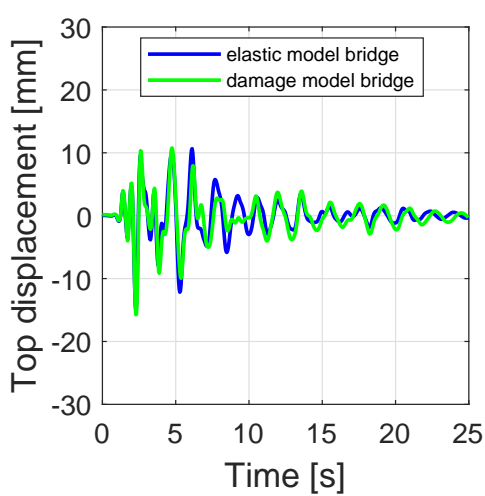

(a)

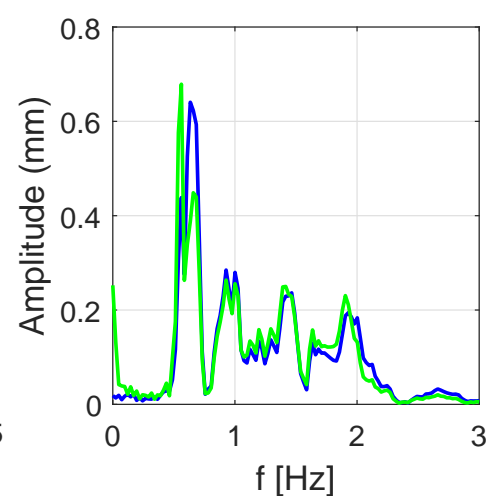

(b)

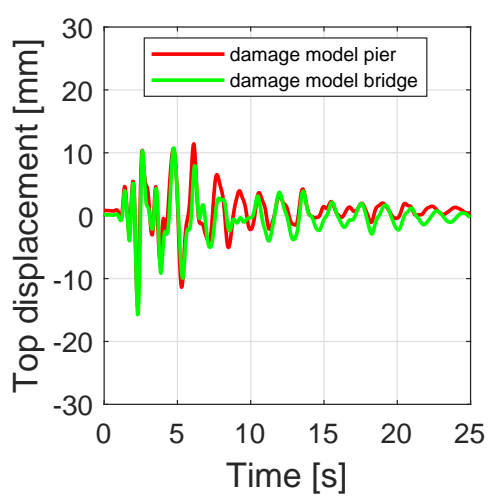

(c)

Figure 12: 'Ponte delle Torri': (a) out-of-plane displacement time-history at point A of the overall brigde for the elastic (blue line) and damage (green line) model under Laino Borgo record; (b) FFT of the out-of-plane displacement time-history in (a) for the elastic (blue line) and damage (green line) model; (c) comparison of the out-of-plane displacement time-history at point A for the overall bridge (green line) and the single pier (red line) in case of damaged response. 


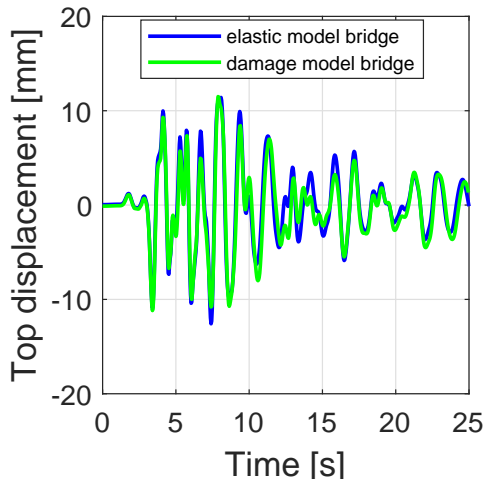

(a)

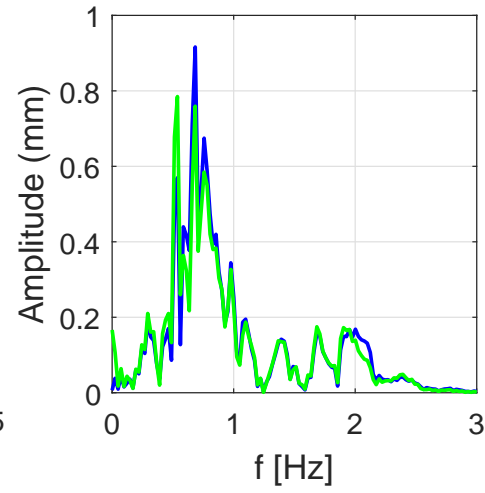

(b)

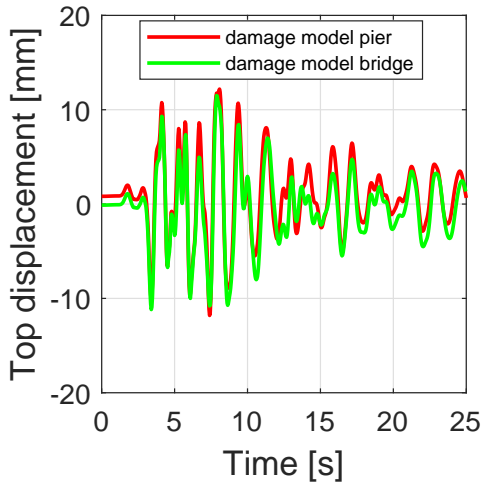

(c)

Figure 13: 'Ponte delle Torri': (a) out-of-plane displacement time-history at point A of the overall brigde for the elastic (blue line) and damage (green line) model under Cesi Monte record; (b) FFT of the out-of-plane displacement time-history in (a) for the elastic (blue line) and damage (green line) model; (c) comparison of the out-of-plane displacement time-history at point A for the overall bridge (green line) and the single pier (red line) in case of damaged response.

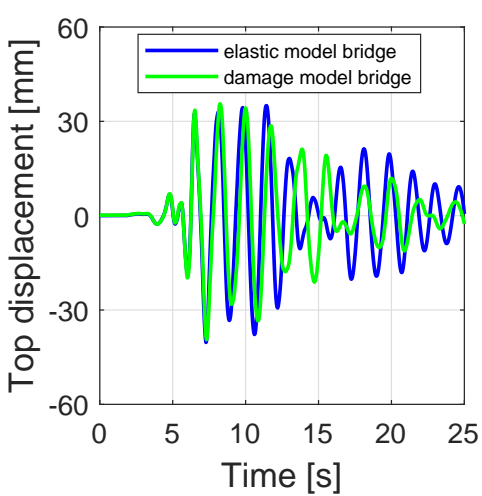

(a)

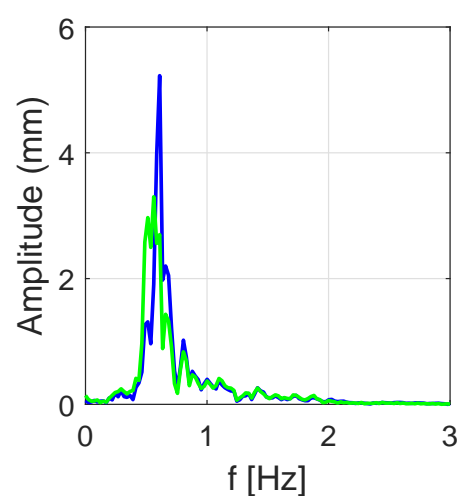

(b)

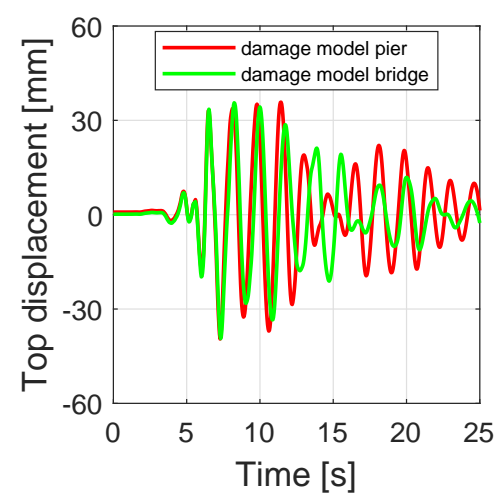

(c)

Figure 14: 'Ponte delle Torri': (a) out-of-plane displacement time-history at point A of the overall brigde for the elastic (blue line) and damage (green line) model under Ussita record; (b) FFT of the out-of-plane displacement time-history in (a) for the elastic (blue line) and damage (green line) model; (c) comparison of the out-of-plane displacement time-history at point A for the overall bridge (green line) and the single pier (red line) in case of damaged response. 


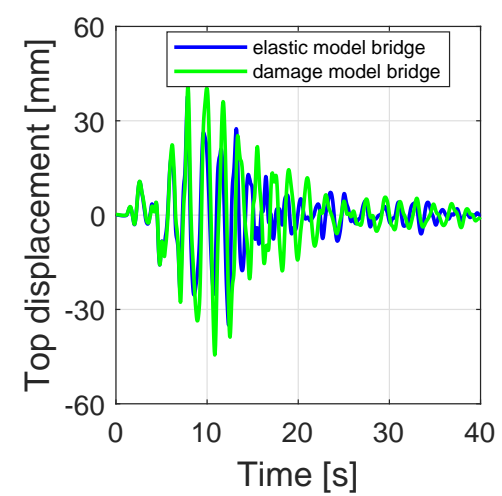

(a)

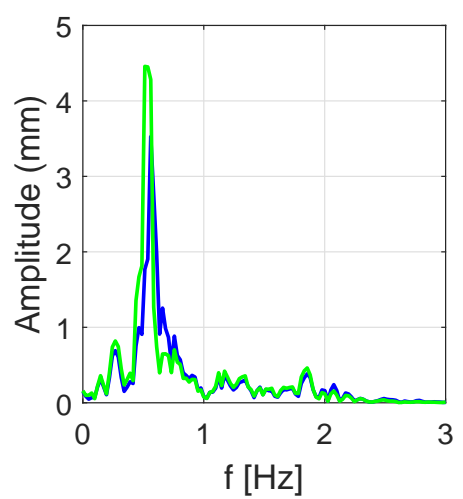

(b)

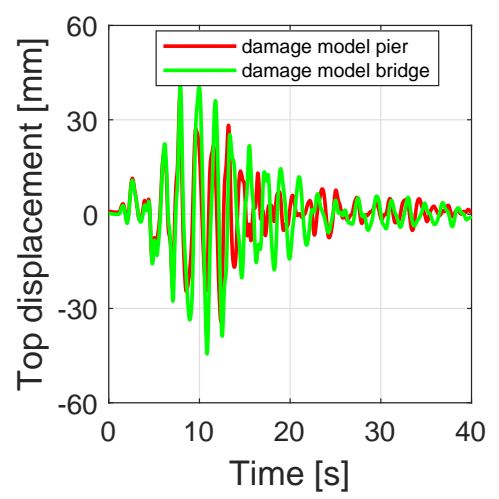

(c)

Figure 15: 'Ponte delle Torri': (a) out-of-plane displacement time-history at point A of the overall brigde for the elastic (blue line) and damage (green line) model under Norcia record; (b) FFT of the out-of-plane displacement time-history in (a) for the elastic (blue line) and damage (green line) model; (c) comparison of the out-of-plane displacement time-history at point A for the overall bridge (green line) and the single pier (red line) in case of damaged response.

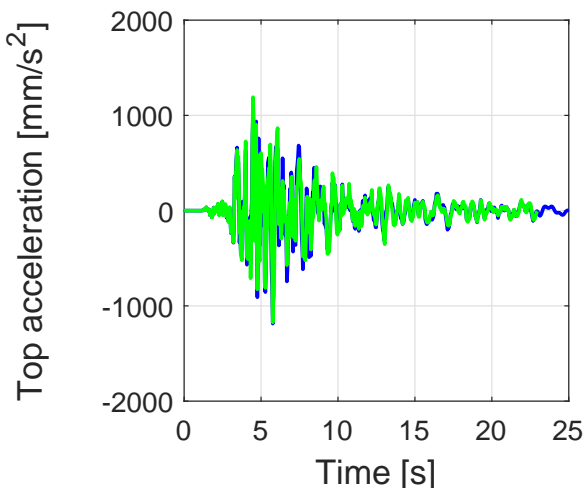

(a)

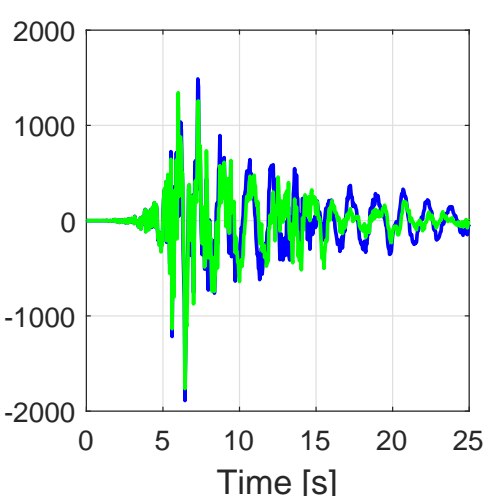

(b)

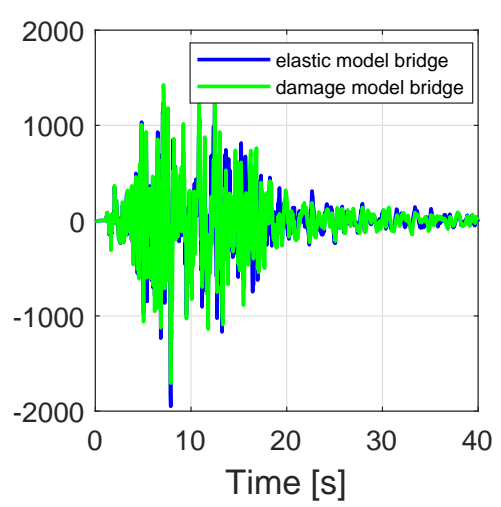

(c)

Figure 16: 'Ponte delle Torri': comparison of the out-of-plane acceleration time-history at point A for the overall bridge under (a) Cesi Monte, (b) Ussita and (c) Norcia records in case of elastic (blue line) and damaged (green line). 


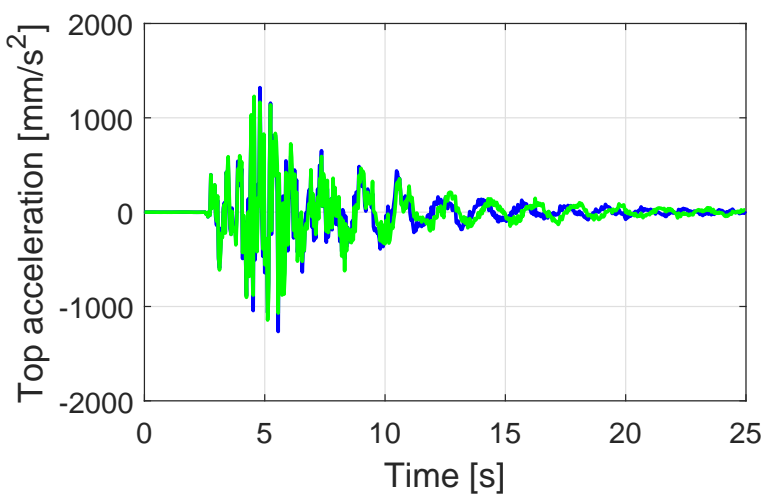

(a)

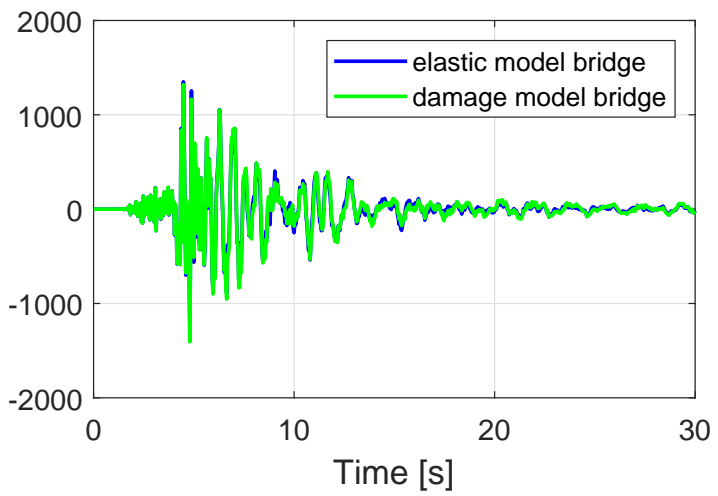

(b)

Figure 17: 'Ponte delle Torri': comparison of the out-of-plane acceleration time-history at point A for the overall bridge under (a) Arquata del Tronto and (b) Amatrice records in case of elastic (blue line) and damaged (green line).

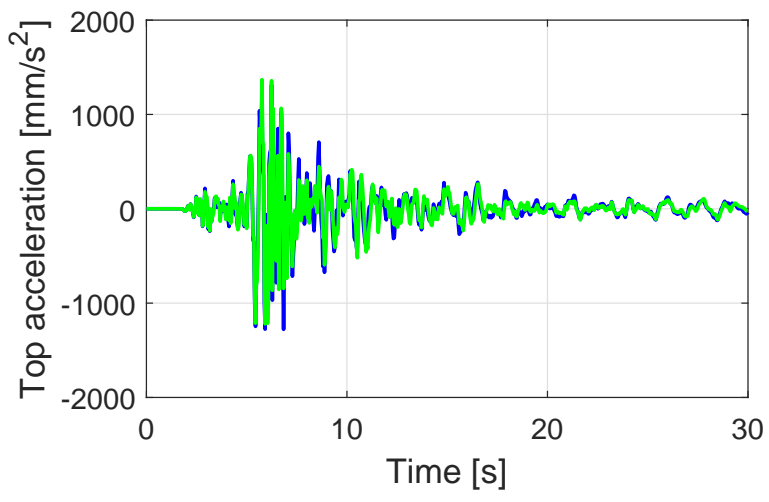

(a)

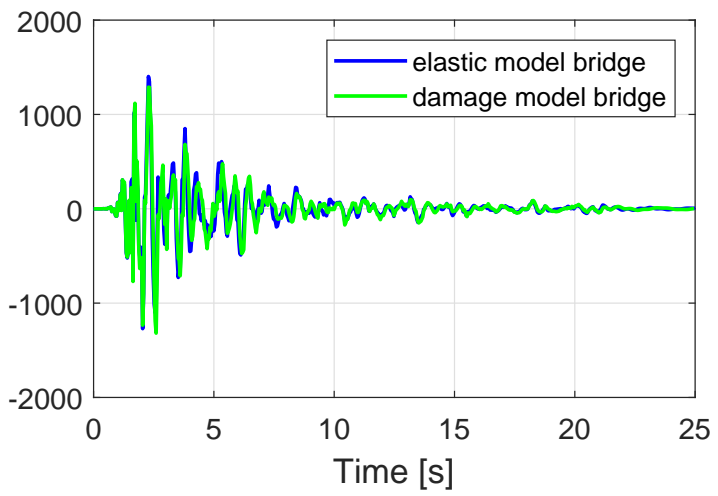

(b)

Figure 18: 'Ponte delle Torri': comparison of the out-of-plane acceleration time-history at point A for the overall bridge under (a) L'Aquila and (b) Laino Borgo records in case of elastic (blue line) and damaged (green line). 

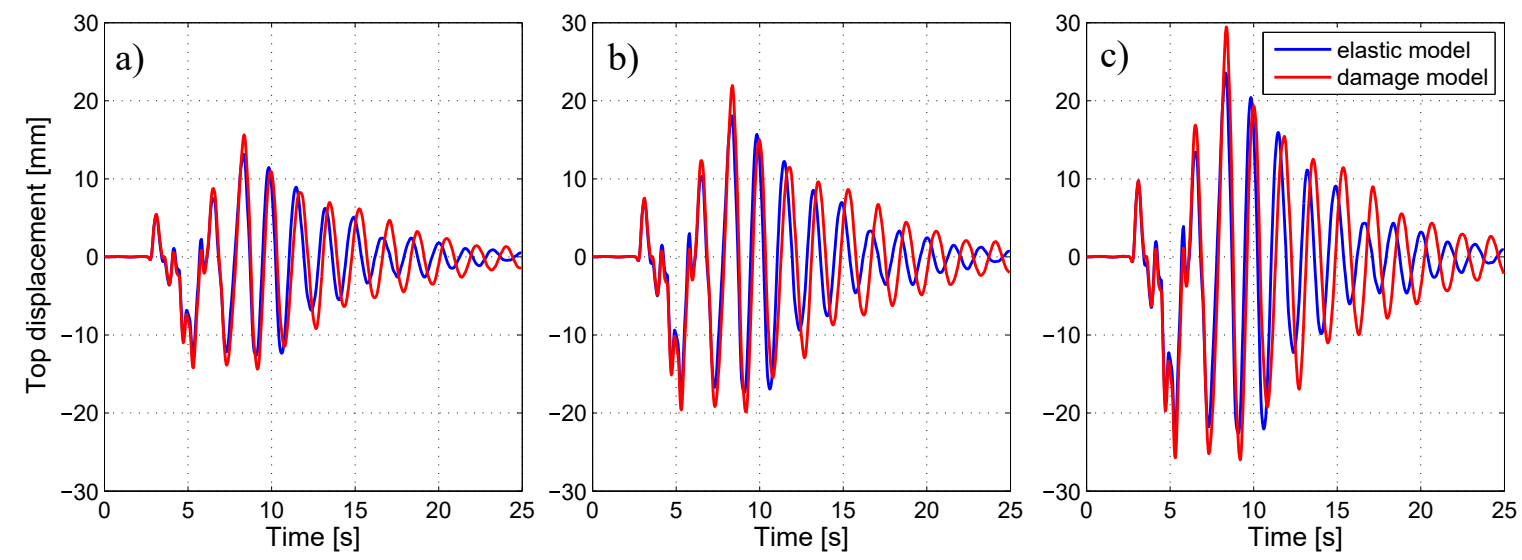

Figure 19: Response under Arquata del Tronto record, out-of-plane displacement at the pier top for the elastic (blue line) and damage model (red line) corresponding to (a) 201-years, (b) 475-years and (c) 975-years return period.
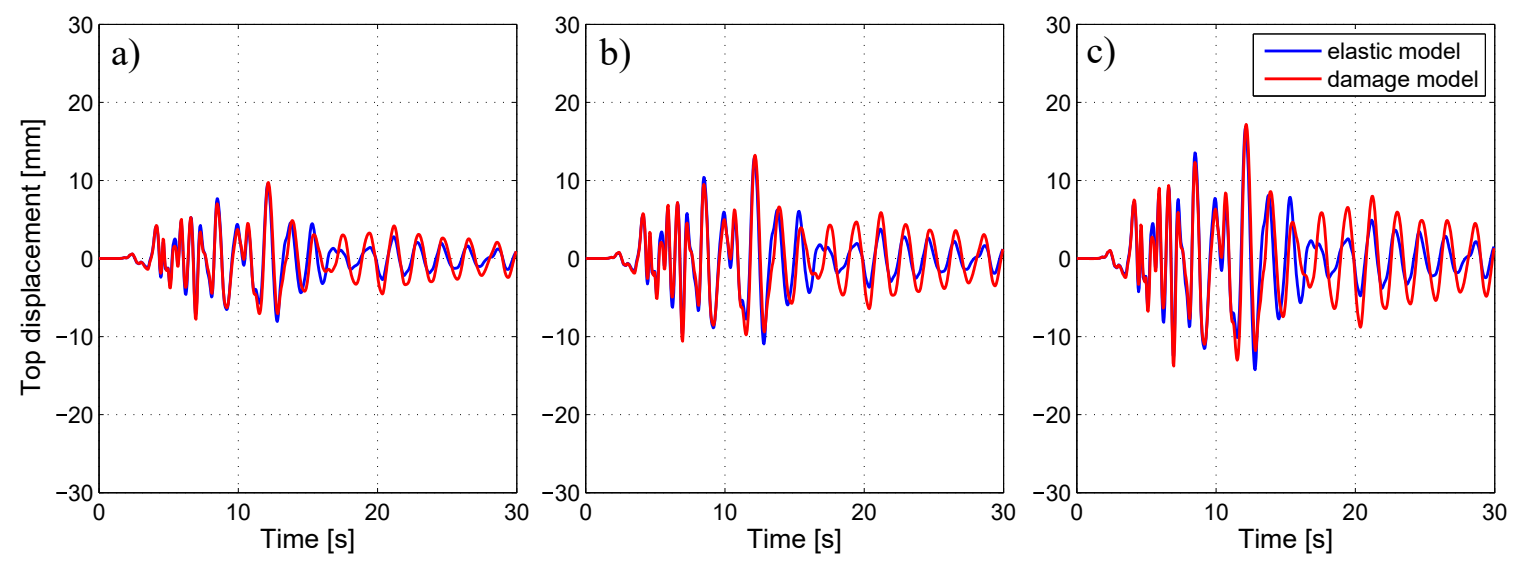

Figure 20: Response under Amatrice record, out-of-plane displacement at the pier top for the elastic (blue line) and damage model (red line) corresponding to (a) 201-years, (b) 475-years and (c) 975-years return period. 

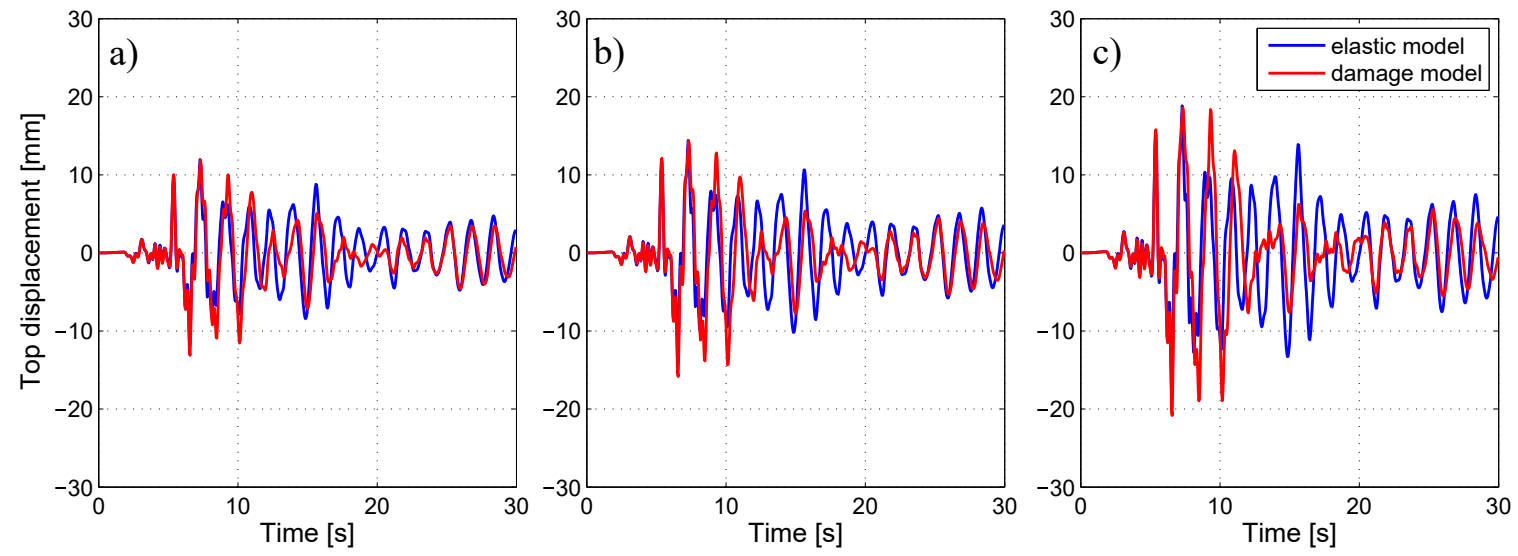

Figure 21: Response under L'Aquila record, out-of-plane displacement at the pier top for the elastic (blue line) and damage model (red line) corresponding to (a) 201-years, (b) 475-years and (c) 975-years return period.
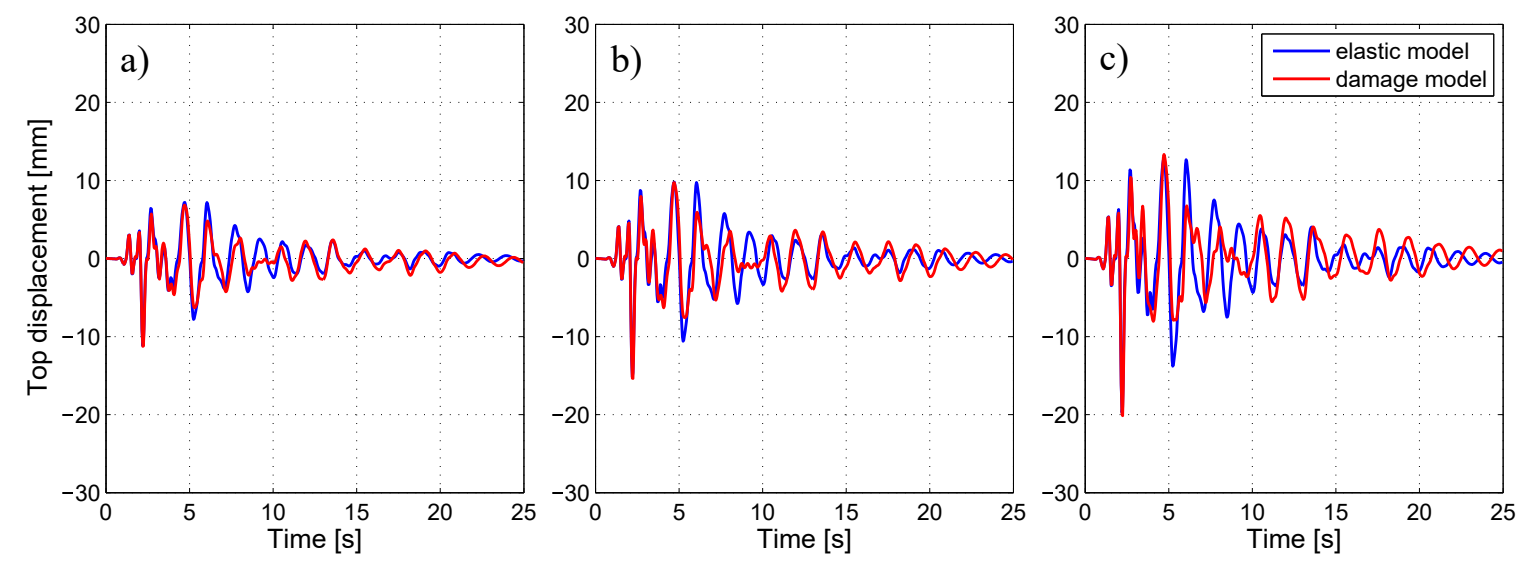

Figure 22: Response under Laino Borgo record, out-of-plane displacement at the pier top for the elastic (blue line) and damage model (red line) corresponding to (a) 201-years, (b) 475-years and (c) 975-years return period. 

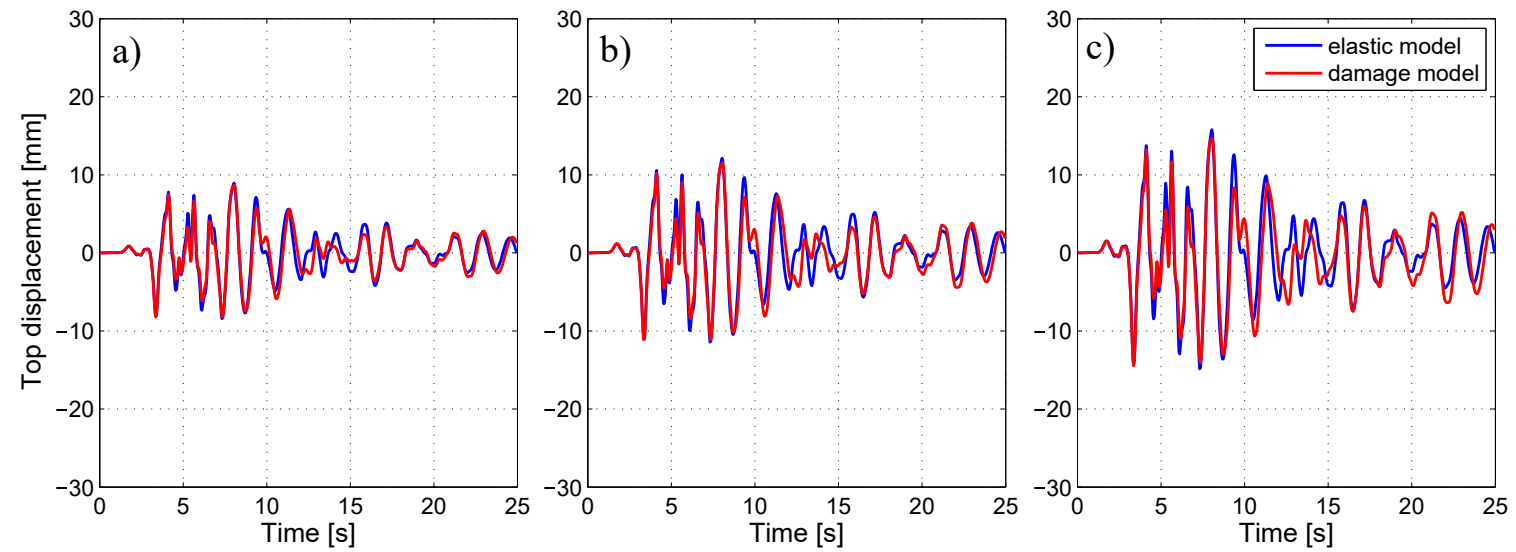

Figure 23: Response under Cesi Monte record, out-of-plane displacement at the pier top for the elastic (blue line) and damage model (red line) corresponding to (a) 201-years, (b) 475 -years and (c) 975-years return period.
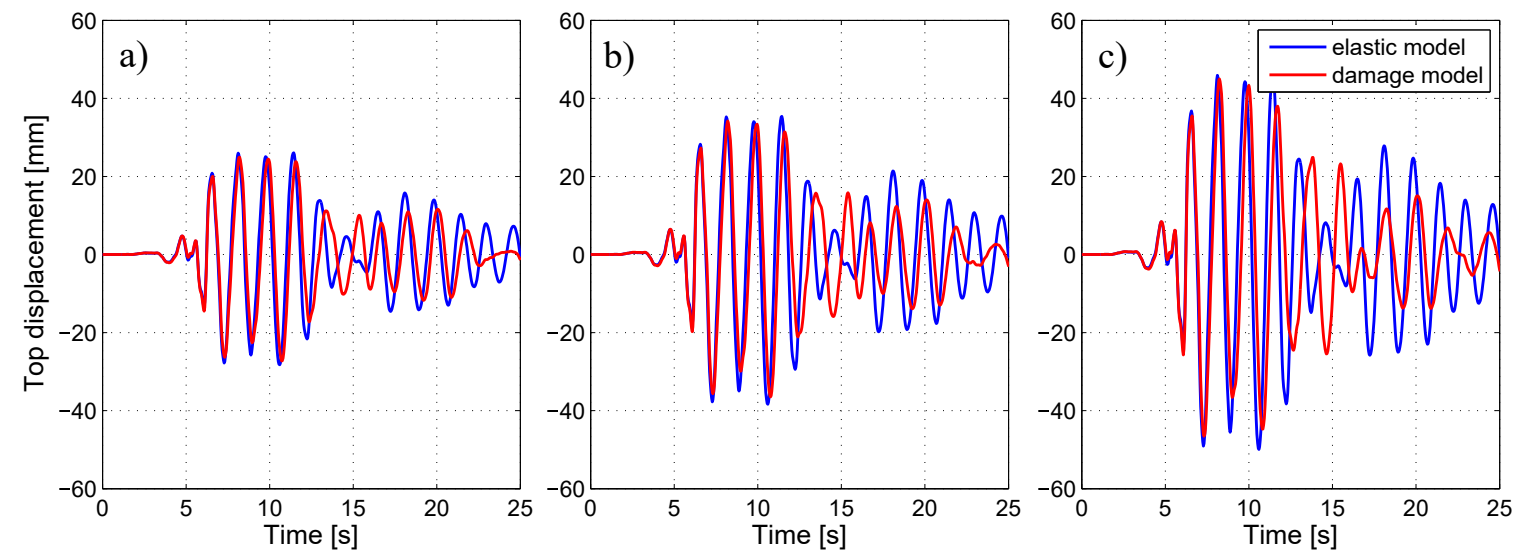

Figure 24: Response under Ussita record, out-of-plane displacement at the pier top for the elastic (blue line) and damage model (red line) corresponding to (a) 201-years, (b) 475-years and (c) 975-years return period. 

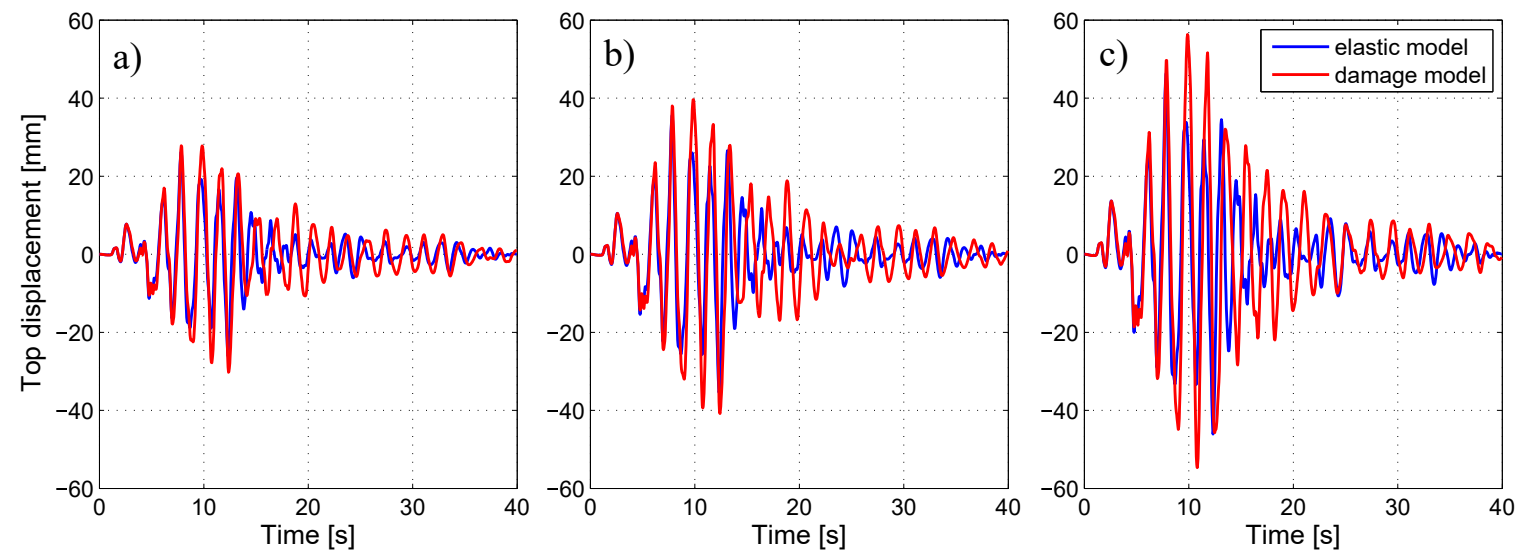

Figure 25: Response under Norcia record, out-of-plane displacement at the pier top for the elastic (blue line) and damage model (red line) corresponding to (a) 201-years, (b) 475-years and (c) 975-years return period.
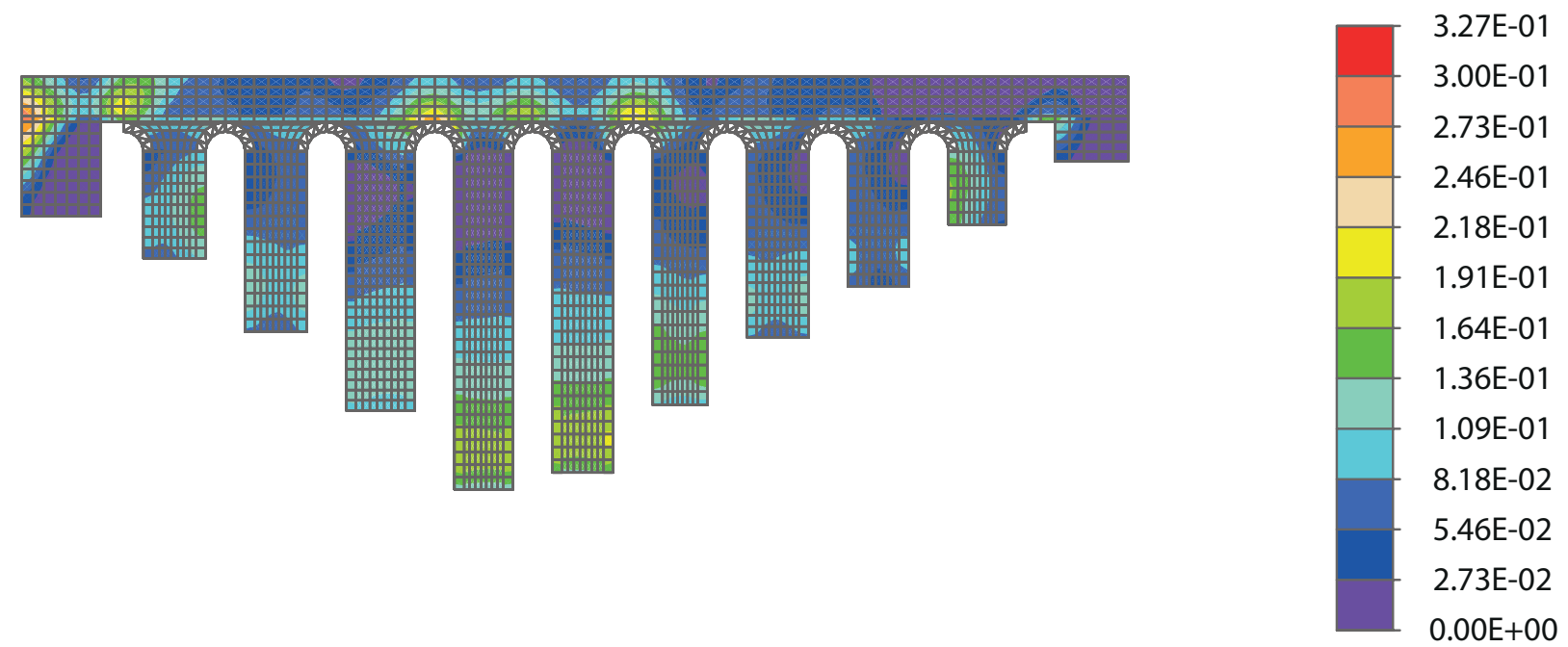

Figure 26: Damage distribution for L'Aquila record scaled at 475-years return period. 

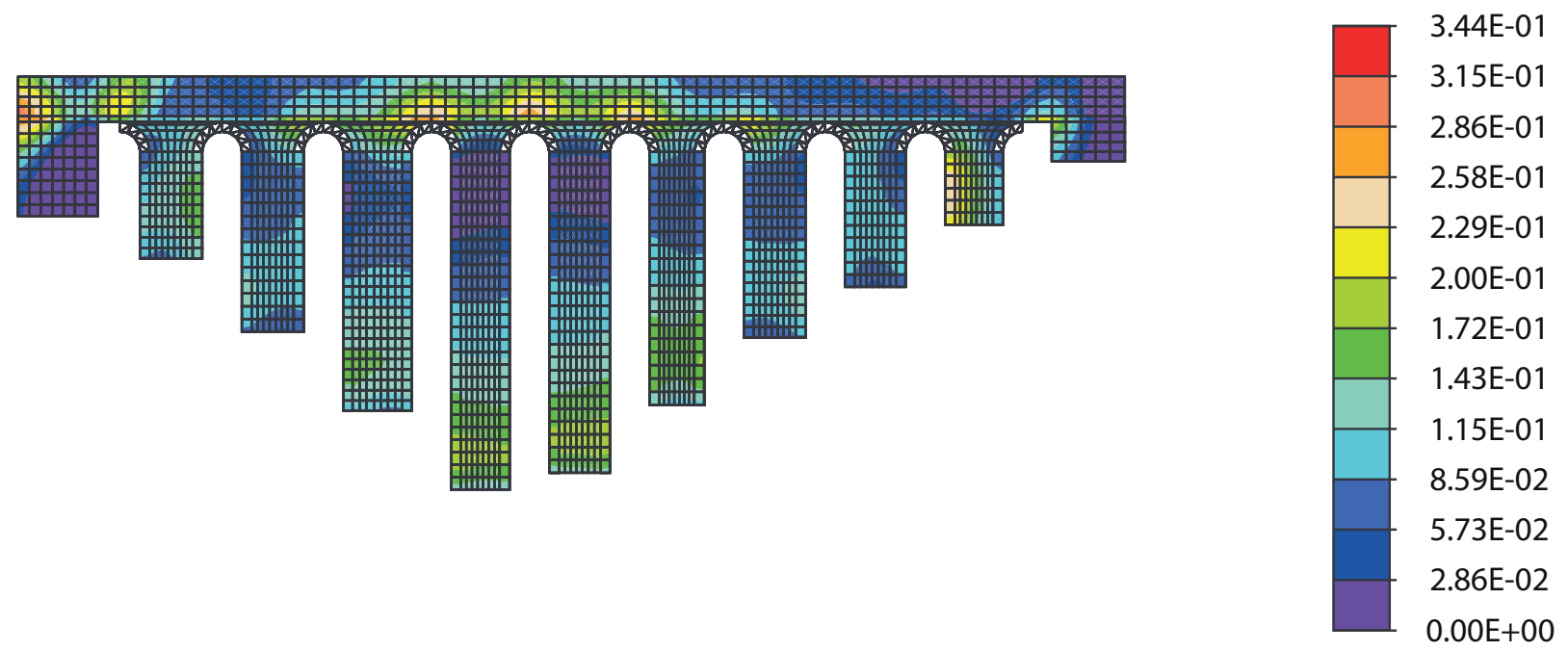

Figure 27: Damage distribution for Laino Borgo record scaled at 475-years return period.
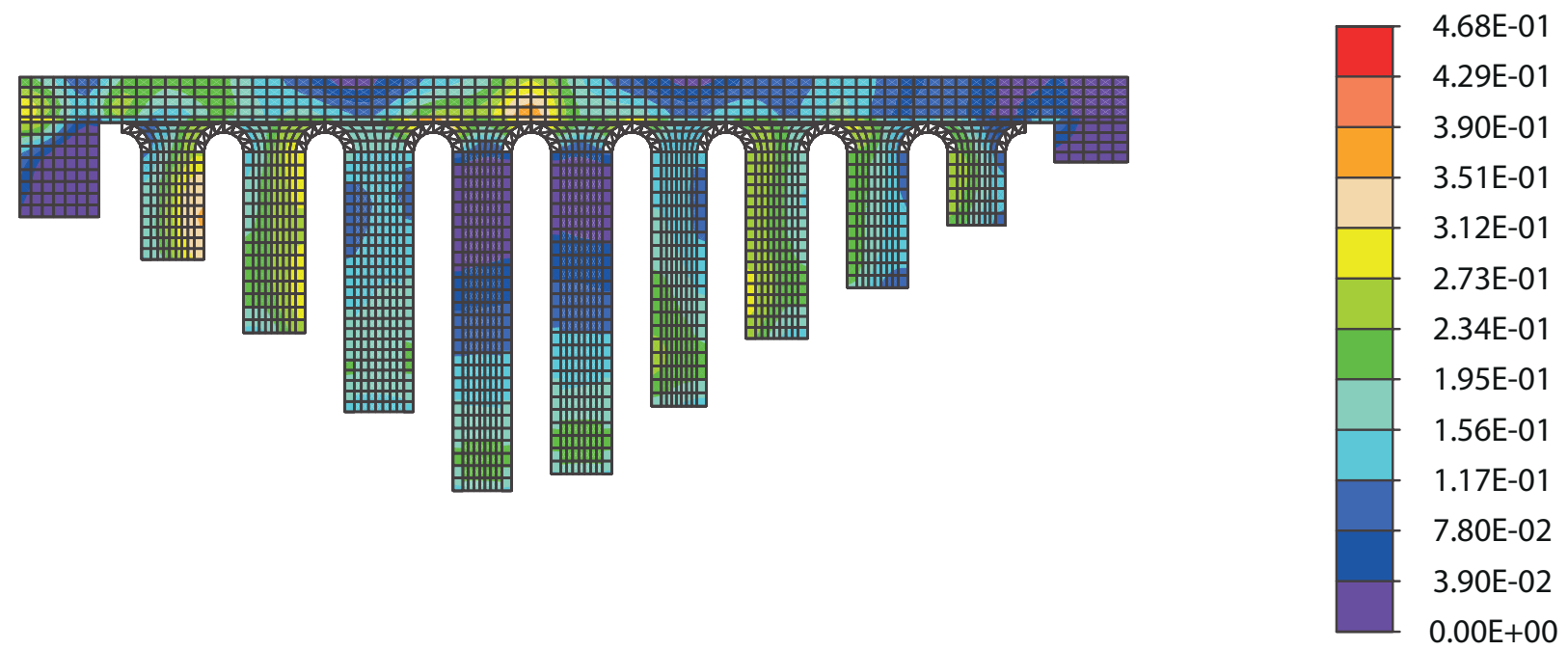

Figure 28: Damage distribution for Norcia record scaled at 475-years return period. 


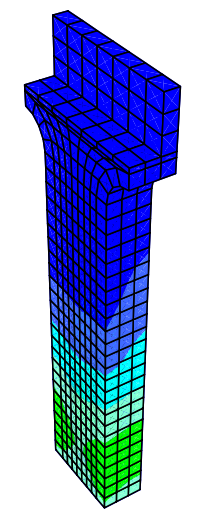

(a)

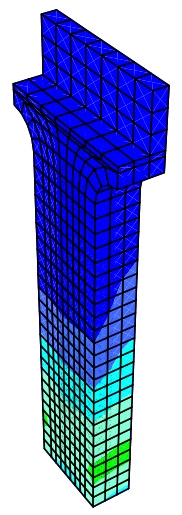

(b)

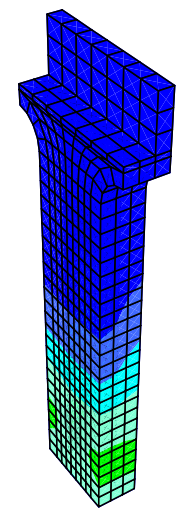

(c)

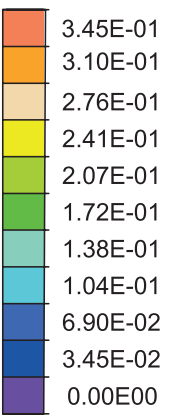

(d)

Figure 29: Damage distribution for records scaled at 201-years return period: (a) L'Aquila, (b) Laino Borgo and (c) Norcia.

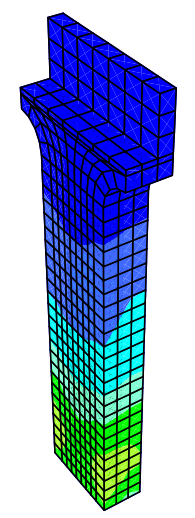

(a)

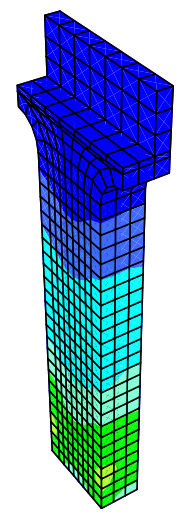

(b)

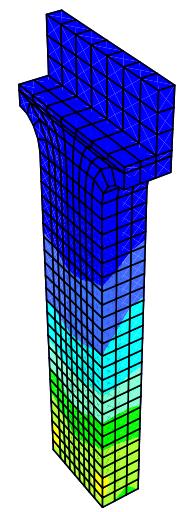

(c)

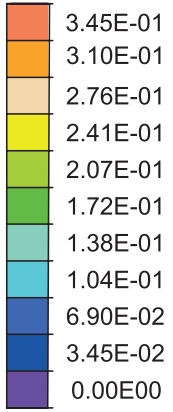

(d)

Figure 30: Damage distribution for records scaled at 475-years return period: (a) L'Aquila (b) Laino Borgo (c) Norcia.

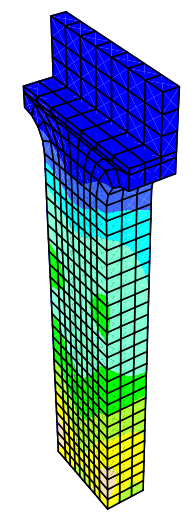

(a)

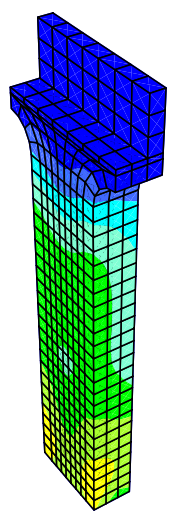

(b)

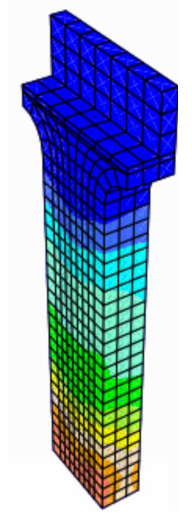

(c)

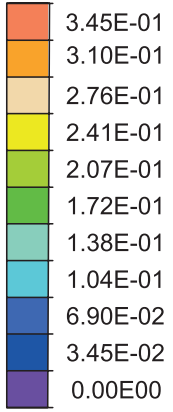

(d)

Figure 31: Damage distribution for records scaled at 975-years return period: (a) L'Aquila (b) Laino Borgo (c) Norcia. 

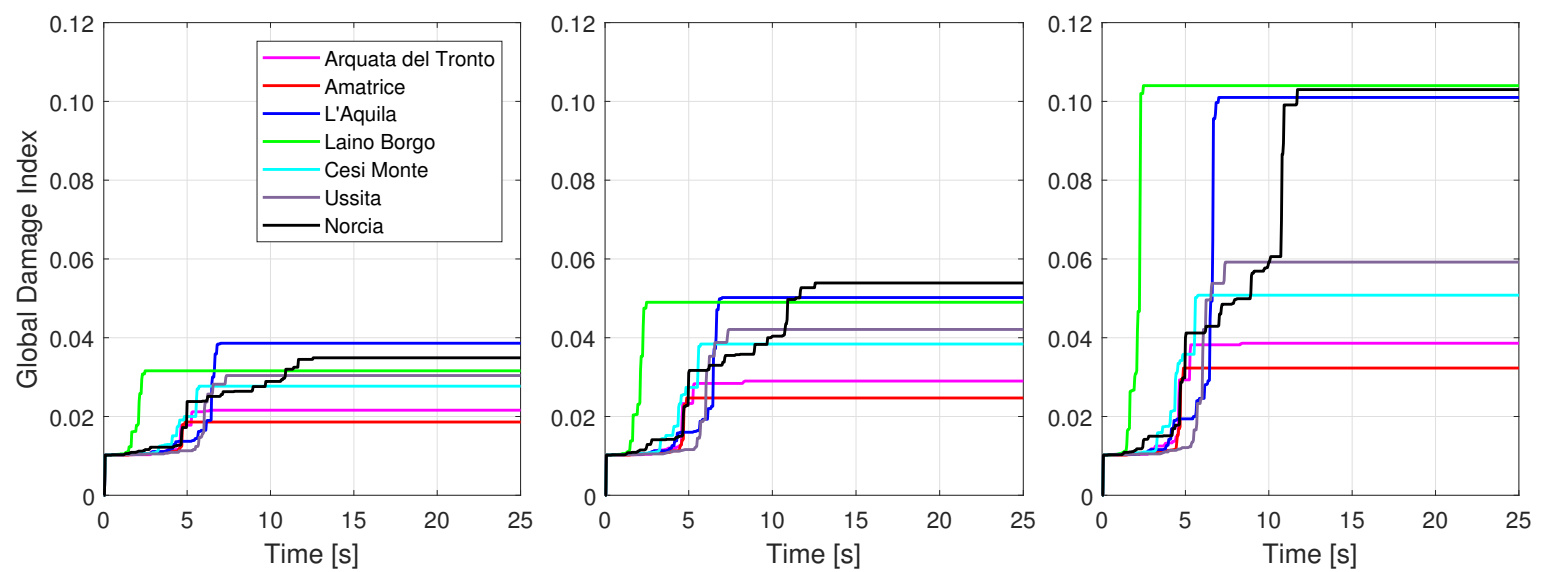

Figure 32: Evolution of the Global Damage Index (GDI) in the pier scaled at return period: (a) 201-years, (b) 475-years and (c) 975-years. 


\begin{tabular}{|c|c|c|c|}
\hline Record & Elastic displacement [mm] & Damage displacement [mm] & Difference \% \\
\hline Arquata del Tronto & 13.07 & 15.65 & 16.5 \\
\hline Amatrice & 9.54 & 9.74 & 2 \\
\hline L'Aquila & 12 & 13.13 & 8.6 \\
\hline Laino Borgo & 11.17 & 11.25 & 0.7 \\
\hline Cesi Monte & 8.94 & 8.69 & -2.8 \\
\hline Ussita & 28.26 & 27.23 & -3.65 \\
\hline Norcia & 26.1 & 30.24 & 13.7 \\
\hline
\end{tabular}

Table 7: Maximum elastic and damage displacement for 201-years return period.

\begin{tabular}{|c|c|c|c|}
\hline Record & Elastic displacement [mm] & Damage displacement [mm] & Difference \% \\
\hline Arquata del Tronto & $17.9(17.92)$ & $22(21.89)$ & $18.63(18.13)$ \\
\hline Amatrice & $12.9(13.33)$ & $13.2(13.07)$ & $2.21(2.7)$ \\
\hline L'Aquila & $14.4(14.05)$ & $15.9(13.07)$ & $9.45(-2.55)$ \\
\hline Laino Borgo & $15.17(15.18)$ & $15.33(15.73)$ & $1(3.49)$ \\
\hline Cesi Monte & $12.12(12.58)$ & $11.5(11.49)$ & $-5.1(-9.48)$ \\
\hline Ussita & $38.38(40.3)$ & $36.49(39.4)$ & $-4.9(-2.28)$ \\
\hline Norcia & $35.43(37.64)$ & $40.81(43.76)$ & $13.2(13.98)$ \\
\hline
\end{tabular}

Table 8: Maximum elastic and damage displacement for 475-years return period.

\begin{tabular}{|c|c|c|c|}
\hline Record & Elastic displacement [mm] & Damage displacement [mm] & Difference \% \\
\hline Arquata del Tronto & 23.41 & 29.23 & 20 \\
\hline Amatrice & 16.8 & 17.2 & 2.06 \\
\hline L'Aquila & 18.37 & 20.83 & 12 \\
\hline Laino Borgo & 19.74 & 20.14 & 2 \\
\hline Cesi Monte & 15.78 & 14.66 & -7 \\
\hline Ussita & 49.94 & 44.71 & -11 \\
\hline Norcia & 46.35 & 55.37 & 16.29 \\
\hline
\end{tabular}

Table 9: Maximum elastic and damage displacement for 975-years return period. 


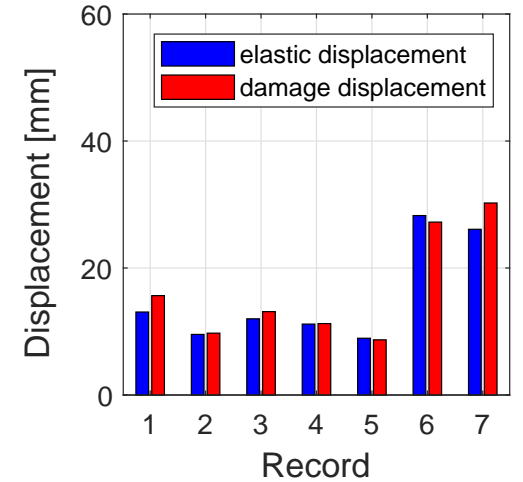

(a)

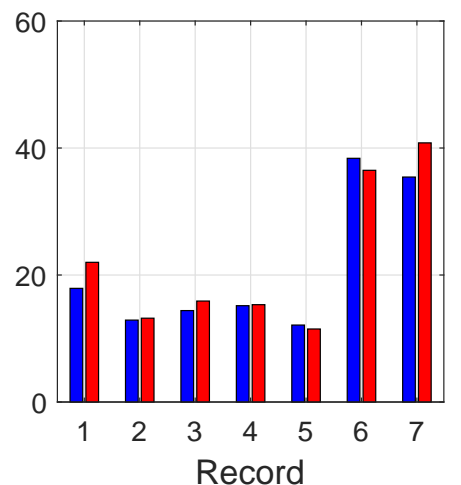

(b)

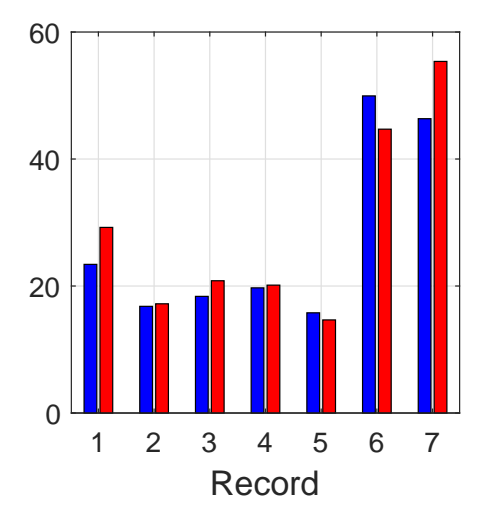

(c)

Figure 33: Maximum elastic and damage displacement for return period (a) 201-years, (b) 475-years and (c) 975-years. Records: 1. Arquata del Tronto, 2. Amatrice, 3. L'Aquila, 4. Laino Borgo, 5. Cesi Monte, 6. Ussita, 7. Norcia.

\begin{tabular}{|c|c|c|c|}
\hline \multirow{2}{*}{ Record } & \multicolumn{3}{|c|}{ TR (years) } \\
\cline { 2 - 4 } & 201 & 475 & 975 \\
\hline Arquata del Tronto & 0.126 & 0.139 & 0.167 \\
\hline Amatrice & 0.121 & 0.131 & 0.146 \\
\hline L'Aquila & 0.161 & 0.189 & 0.256 \\
\hline Laino Borgo & 0.142 & 0.179 & 0.232 \\
\hline Cesi Monte & 0.135 & 0.159 & 0.193 \\
\hline Ussita & 0.134 & 0.160 & 0.223 \\
\hline Norcia & 0.146 & 0.216 & 0.345 \\
\hline
\end{tabular}

Table 10: Maximum local damage at the final step of the analysis. 


\section{Conclusions}

The nonlinear dynamic behavior of 'Ponte delle Torri' in Spoleto, Italy, has been investigated. To account for the main nonlinear degrading mechanisms, typically occurring in masonry material, an isotropic damage model has been adopted to evaluate masonry bridge response under seismic actions. The evolution of the damage in the structure, driven by an equivalent strain measure defined on the basis of the principal strains, has been monitored and its effects on the bridge dynamic response explored. The nonlinear 3D brick finite element presented in [4] and implemented in the FEAP code has been adopted to perform the numerical analyses. To overcome mesh-dependency problems due to the adopted material constitutive law with strain-softening, a nonlocal integral procedure has been introduced in FEAP, evaluating the damage associated variable at each Gauss integration point, that is evaluating the equivalent strain measure, as a weighted average on a properly defined neighborhood of the point. This has allowed to regularize the numerical response and avoid localization problems. To perform the nonlinear dynamic analyses of the studied bridge, a set of seven natural earthquake records has been selected according to the design spectrum specified by the Italian Building Code and considering three different return periods. Thus, a single pier, sized to get the same first natural frequency of the entire bridge, has been dynamically analyzed under the chosen records. In particular, the out-of-plane displacement experienced at the top of the pier has been monitored, comparing the bridge damaged response with that evaluated in case of material elastic behavior. The evolution of the Global structural Damage Index has also been investigated. The analysis of the dynamic out-of-plane response of the single pier allowed to significantly reduce the computational efforts and gave important information about the entire bridge dynamic behavior, mainly in case of applied records that excite the first out-of-plane frequency of the bridge. The analyses performed on the whole bridge provided important information on damage distribution. In particular, it can be noticed that significant damage occurs over the central arches, due to horizontal bending, and at the east abutment (Monteluco hill) where soil slope is steeper. Taking into consideration the seismic history of the site, consisting of several events with MCS intensity greater than or VII, the evolution and the final values of the Global Damage Index appeared consistent with the observed damage, with cracks or spalling which can be classified of medium or high gravity [10]. The results have shown that the effects of the damage onset and progression can strongly modify the bridge response, depending on the dynamic characteristics of the applied record. Two main phenomena emerged: damage caused a reduction of the initial stiffness and this, in turn, entailed an increase of the bridge natural periods. As already pointed out in [18] with reference to masonry walls, onset and propagation of damaging 
mechanisms in the masonry structures substantially modify their mechanical properties and, as a consequence, their natural frequencies (periods) decrease (increase). In other words, damage strongly changes the dynamic structural response, influencing the natural periods, the displacements amplification and the resonance conditions. As expected, the increase of period entails a general increase of displacement amplitudes, as reported in Tables 7, 8, 9 and Figure 33. However, this effect only holds on the average, and cases can be observed, namely Cesi Monte and Ussita, where the increase of period entails a reduction of displacements, due to the non-smooth character of the response spectrum. Future work will investigate the effect of different ground motions on a more systematic basis, as well as the effect of sequences of earthquakes and the application of the damage model to different types of masonry structures.

\section{Acknowledgement and Compliance with Ethical Standards}

Acknowledgement: The authors are grateful to Prof. Luigi Sorrentino for the help provided in developing the seismic catalogue of Spoleto.

Funding: This study was funded by MIUR-PRIN, University of Rome Sapienza.

Conflict of Interest: The authors declare that they have no conflict of interest.

\section{References}

[1] NTC 2008. Italian Building Code for the Constructions (Norme Tecniche per le Costruzioni). D.M. 14 January 2008 - S.O. n.30, G.U. n.29 - 4; February 2008 [in Italian].

[2] D. Addessi. A 2D Cosserat finite element based on a damage-plastic model for brittle materials. Computers and Structures, 135:20 - 31, 2014.

[3] D. Addessi and E. Sacco. Enriched plane state formulation for nonlinear homogenization of in-plane masonry wall. Meccanica, 51(11):2891-2907, 2016.

[4] D. Addessi and E. Sacco. Nonlinear analysis of masonry panels using a kinematic enriched plane state formulation. International Journal of Solids and Structures, 90:194$214,2016$.

[5] Daniela Addessi and Elio Sacco. Homogenization of heterogeneous masonry beams. Meccanica, 53(7):1699-1717, 2018. 
[6] C. Bandini. Il monte, il ponte, il fonte. Claudio Argentieri: Spoleto, 1921 (in Italian).

[7] Z. P. Bazant and M. Jirasek. Nonlocal integral formulations of plasticity and damage: survey of progress. Journal of Engineering Mechanics ASCE, 128(11):1119-1149, 2002.

[8] L. Berto, A. Saetta, R. Scotta, and R. Vitaliani. An orthotropic damage model for masonry structures. International Journal for Numerical Methods in Engineering, 55:127$157,2002$.

[9] N. Challamel, C. Lanos, and C. Casandjian. Strain-based anisotropic damage modelling and unilateral effects. International Journal of Mechanical Sciences, 47:459-473, 2005.

[10] F. Cluni, V. Gusella, and L. Marchetti. Present state and vulnerability of Ponte delle Torri, Spoleto. Proceedings of the 11th Italian Conference on Earthquake Engineering, Genoa, 2004 (in Italian).

[11] G. De Canio, M. Mongelli, I. Roselli, A. Tatì, D. Addessi, M. Nocera, and D. Liberatore. Numerical and operational modal analyses of the 'Ponte delle Torri', Spoleto, Italy. Proceedings of the 10th European Conference on SAHC, Louven, 2016.

[12] L.D. Decanini and F. Mollaioli. On the attenuation of the macroseismic intensity in some Italian seismogenetic zones. Proceedings of the 8th Italian Conference on Earthquake Engineering, Taormina, pages 895-902, 1997 (in Italian).

[13] L. Di Sarno, F. da Porto, G. Guerrini, P.M. Calvi, G. Camata, and A. Prota. Seismic performance of bridges during the 2016 Central Italy earthquakes. Bulletin of Earthquake Engineering, pages 1573-1456, 2018.

[14] N. Domede, A. Sellier, and T. Stablon. Structural analysis of a multi-span railway masonry bridge combining in situ observations, laboratory tests and damage modelling. Engineering Structures, 56:837-849, 2013.

[15] P.J. Fanning and T.E. Boothby. Three-dimensional modelling and full-scale testing of stone arch bridges. Computers \& Structures, 79(29):2645-2662, 2001.

[16] S. Fichant, C. La Borderie, and G. Pijaudier-Cabot. Isotropic and anisotropic descriptions of damage in concrete structures. Mechanics of Cohesive-Frictional Materials, 4:339-359, 1999. 
[17] L. Gambarotta and S. Lagomarsino. Damage models for the seismic response of brick masonry shear walls Part I: the mortar joint model and its application. Earthquake Engineering and Structural Dynamics, 26:423-439, 1997.

[18] C. Gatta, D. Addessi, and F. Vestroni. Static and dynamic nonlinear response of masonry walls. International Journal of Solids and Structures, 155:291-303, 2018.

[19] M. Gioffrè, V. Gusella, and F. Cluni. Performance evaluation of monumental bridges: testing and monitoring 'Ponte delle Torri' in Spoleto. Structure and Infrastructure Engineering, 4:95-106, 2008.

[20] D. Halm and A. Dragon. A model of anisotropic damage by mesocrack growth; unilateral effect. International Journal of Damage, 5(4):384-402, 1996.

[21] M. Locati, R. Camassi, and M. Stucchi. DBMI11, la versione 2011 del Database Macrosismico Italiano. Milano, Bologna, available online: http://emidius. mi. ingv. it/DBMI11, 2011.

[22] P.B. Lourenço, J.G. Rots, and J. Blaauwendraad. Continuum model for masonry: parameter estimation and validation. Journal of Structural Engineering, 124(6):642-652, 1998.

[23] L. Luzi, F. Pacor, and R. Puglia. Italian Accelerometric Archive v 2.1. Istituto Nazionale di Geofisica e Vulcanologia, Dipartimento della Protezione Civile Nazionale, 2016.

[24] L. Luzi, R. Puglia, E. Russo, and ORFEUS WG5. Engineering Strong Motion Database, version 1.0. Istituto Nazionale di Geofisica e Vulcanologia, Observatories \& Research Facilities for European Seismology, 2016.

[25] T. J. Massart, R. H. J. Peerlings, and M. G. D. Geers. An enhanced multi-scale approach for masonry wall computations with localization of damage. International Journal for Numerical Methods in Engineering, 69(5):1022-1059, 2007.

[26] J. Mazars and G. Pijaudier-Cabot. Continuum damage theory-application to concrete. Journal of Engineering Mechanics, 115:345-365, 1989.

[27] L. Pelà, A. Aprile, and A. Benedetti. Comparison of seismic assessment procedures for masonry arch bridges. Construction and Building Materials, 38:381-394, 2013.

[28] P. Pijaudier-Cabot and Z. L. Bazant. Non local damage theory. Journal of Engineering Mechanics ASCE, 118(10):1512-1533, 1987. 
[29] P. Roca, M. Cervera, G. Gariup, and L. Pelà. Structural analysis of masonry historical constructions. Classical and advanced approaches. Archive of Computational Methods in Engineering, 17:299-325, 2010.

[30] I. Roselli, M. Malena, M. Mongelli, N. Calavagli, M. Gioffrè, G. De Canio, and G. de Felice. Health assessment and ambient vibration testing of the "Ponte delle Torri" of Spoleto during the 2016-2017 Central Italy seismic sequence. Journal of Civil Structural Health Monitoring, 8(2):199-216, 2018.

[31] A. Rovida, R. Camassi, P. Gasperini, and M. Stucchi. CPTI11, la versione 2011 del Catalogo Parametrico dei Terremoti Italiani. Milano, Bologna, 2011.

[32] A. Sansi. History of the Municipality of Spoleto. Vol. I-VIII. Accademia Spoletina: Spoleto, 1884 (in Italian).

[33] L. Sorrentino, L. Liberatore, D. Liberatore, and R. Masiani. The behaviour of vernacular buildings in the 2012 Emilia earthquakes. Bulletin of Earthquake Engineering, 12(5):2367-2382, 2014.

[34] Luigi Sorrentino, Serena Cattari, Francesca da Porto, Guido Magenes, and Andrea Penna. Seismic behaviour of ordinary masonry buildings during the 2016 central Italy earthquakes. Bulletin of Earthquake Engineering, Apr 2018.

[35] R.L. Taylor. FEAP-A finite element analysis program, Version 8.5. Department of Civil and Environmental Engineering, University of California at Berkeley, California, 2017.

[36] Jessica Toti, Vincenzo Gattulli, and Elio Sacco. Nonlocal damage propagation in the dynamics of masonry elements. Computers \& Structures, 152:215 - 227, 2015. 